\title{
3D scour below pipelines under waves and combined waves and currents
}

\author{
Liang Cheng a,c,*, Kervin Yeow ${ }^{a}$, Zhipeng Zang ${ }^{b}$, Fangjun Li $^{\mathrm{d}}$ \\ a School of Civil and Resource Engineering, University of Western Australia, 35 Stirling Highway, Crawley, WA 6009, Australia \\ b Institute of Mechanics, Chinese Academy of Sciences, 15 Beisihuanxi Road, Beijing 100190, China \\ c Stake Key Laboratory of Coastal and Offshore Engineering, Dalian University of Technology, Dalian 116024, China \\ ${ }^{d}$ Department of Transport, 1 Essex Street, Fremantle, WA 6160, Australia
}

\section{A R T I C L E I N F O}

\section{Article history:}

Received 21 May 2013

Received in revised form 29 September 2013

Accepted 3 October 2013

Available online 6 November 2013

\section{Keywords:}

Pipeline

Scour

Free span

Scour rates

Waves

Combined wave and current

\begin{abstract}
A B S T R A C T
This paper presents the results of an experimental investigation on three-dimensional local scour below a rigid pipeline subjected to wave only and combined wave and current conditions. The tests were conducted in a conventional wave flume. The major emphasis of the investigation was on the scour propagation speed (free span expansion rate) along the pipeline after local scour was initiated at a controlled location. The effects of flow ratio (steady current velocity vs. combined waves/current velocity), flow incidence angle and pipeline initial embedment depth on free span expansion rate were investigated. It was observed that the scour along the pipeline propagated at a constant rate under wave only conditions. The scour propagation rate decreased with increasing embedment depth, however, increased with the increasing Keuglegan-Carpenter (KC) number. Under combined wave and current conditions, the effect of velocity ratio on scour propagation velocity along the pipeline was quantified. Empirical relationships between the scour propagation rate $\left(V_{h}\right)$ and key parameters such as the KC number and embedment depth (e/D) were established based on the testing results.
\end{abstract}

(c) 2013 Elsevier B.V. All rights reserved.

\section{Introduction}

Local scour below offshore pipelines has been the topic of a number of research projects over the past three decades due to its engineering significance. Local scour can be initiated at a number of locations along the pipeline as the results of either the piping mechanism or uneven seabed after installation of the pipeline. Once a local scour is initiated somewhere alone a pipeline, it spreads along the pipeline to form free spans. Free spans were often identified as culprits for pipeline failures in the pipeline industry because free-spanned pipelines are more susceptible to structural damages related to over-stressing, fatigue and human activities. Research on pipeline stability (Jas et al., 2012; Palmer, 1996), however, showed that free spans can be beneficial for pipeline stability. Formation of free spans can lead to natural selfburial or sinking of offshore pipelines into the scour holes formed below the pipelines. As the free spans further develop during the storm, the pipeline may sag into the scour hole as the result of structural deflections or extra penetrations into the seabed at span shoulders. As the pipeline sags into a scour hole, it deflects more flow towards the top side of pipeline. This leads to a reduction of sediment transport capacity directly below the pipeline. The scour hole will then be backfilled with sediments and this induces the natural self-burial of the pipeline (Cheng et al., 2009; Sumer and Fredsøe, 2002). Pipeline stability is significantly enhanced through hydrodynamic shielding

\footnotetext{
* Corresponding author at: School of Civil and Resource Engineering, University of Western Australia 35 Stirling Highway, Crawley Western Australia 6009, Australia.
}

and the increase of lateral soil resistance once it is buried or sags into a scour hole.

Most of the early studies on local scour below pipelines were concerned with the so-called two dimensional scour in the plane perpendicular to the pipeline, which is a simplification of three dimensional scour blow offshore pipelines. Issues of engineering significance regarding two-dimensional scour subject to waves and combined waves/current have been studied and are relatively well understood. This includes the onset of scour (Chiew, 1990; Sumer and Fredsøe, 1991; Sumer et al., 2001), equilibrium scour depth (Bernetti et al., 1990; Hansen, 1992; Lucassen, 1984; Sumer and Fredsøe, 1990; Sumer and Fredsøe, 1996), and time scale of local scour (Fredsøe et al., 1992). The effects of vortex shedding (Jensen et al., 1989; Sumer and Fredsøe, 1991; Sumer and Fredsøe, 1997), the KC number (Cevik and Yuksel, 1999; Gokce and Gunbak, 1991; Hansen, 1992; Lucassen, 1984; Sumer and Fredsøe, 1990) and the combined wave/current parameter on local scour are also relatively well investigated. Through the literature, the velocity ratio of $m=U_{c} /\left(U_{c}+U_{w}\right)$ was also identified as the governing parameter for scour in combined waves/current conditions (Bernetti et al., 1990; Hansen, 1992; Lucassen, 1984; Sumer and Fredsøe, 1996), where $U_{c}$ is the flow velocity due to current and $\mathrm{U}_{\mathrm{w}}$ is the wave orbital velocity. Various numerical models for predicting two dimensional scour processes have also been developed in recent years. However this has been limited to currents only or waves only conditions (Boros, 1999; Li and Cheng, 1999, 2002; Liang and Cheng, 2005a, 2005b; Liang et al., 2005, among others).

Study on local scour propagation along pipelines (three-dimensional scour) has been limited. Fredsøe et al. (1988) described the process of 
pipeline sagging into a three-dimensional scour hole and the follow-up process of backfilling in a current only situation. Bernetti et al. (1990) proposed a simple empirical model for analysing the longitudinal propagation of a scour hole. This model was later improved by Hansen et al. (1991) to account for parameters that may slow down the scouring process such as pipeline embedment and sagging. Cheng et al. (2009) conducted an experimental investigation on the propagation of scour along pipelines subject to steady currents under live-bed conditions. Physical model experiments were conducted to quantify the effects of various parameters on scour propagation velocities along the pipeline. Local scour depths directly below the model pipeline were measured. Effects of various parameters such as pipeline embedment depth, the incoming flow Shields parameter and flow incident angle to the pipeline on scour propagation velocities along the pipeline were investigated. It was found that scour propagation velocities generally increase with the increase of the Shields parameter but decrease with the increase of the pipeline embedment depth. A general predictive formula for scour propagation velocities along the pipeline was proposed and validated against the experimental results. Wu and Chiew $(2012,2013)$ carried out an experimental investigation of three dimensional scour below different diameter model pipes subject to steady currents under clear water conditions. It was found that scour propagation velocity is also dependent on the Froude number, in addition to other parameters such as pipeline initial embedment depth.

This paper presents the experimental results on scour propagation along pipelines subject to wave only and combined wave and current conditions. The work reported in this paper can be considered as an extension of the investigation by Cheng et al. (2009). Local scour depths directly below the model pipeline were measured using conductivity scour probes in the same way as described in Cheng et al. (2009). Relationships between the scour propagation rate $\left(\mathrm{V}_{\mathrm{h}}\right)$ and the key parameters such as the Keuglegan-Carpenter number (KC), embedment depth (e/D) and wave angle of attack are established. In addition, the effect of velocity ratio $\mathrm{m}$ on scour propagation speeds along the pipeline is quantified.

\section{Experiment setup}

The experiments were conducted in an environmental wave and current flume located at the State Key Laboratory of Coastal and Offshore Engineering, Dalian University of Technology. The environmental test flume is $50 \mathrm{~m}$ in length, $4 \mathrm{~m}$ in width and $2.5 \mathrm{~m}$ in depth. It is equipped with an irregular wave maker that can generate both regular and irregular waves, and a bi-directional current making system. The maximum water depth can be up to $2.0 \mathrm{~m}$, maximum wave height about $0.6 \mathrm{~m}$ and wave period from $0.5 \mathrm{~s}$ to $5 \mathrm{~s}$. The maximum pump capacity is $1 \mathrm{~m}^{3} / \mathrm{s}$. A total of 125 tests were conducted in the testing programme, which included 60 wave only tests and 65 tests under combined wave and current conditions. The water depth was maintained at a constant of $0.45 \mathrm{~m}$ in all the tests. A $4 \mathrm{~m}$ long and 0.25 $\mathrm{m}$ deep sand-pit, supported by 1:20 concrete slopes on both ends, was constructed as the test section. The upstream end of the sand-pit was
$14 \mathrm{~m}$ from the wave maker, and the downstream end was $7 \mathrm{~m}$ from the perforated stone beach. A schematic experimental setup is shown in Fig. 1.

A $4 \mathrm{~m}$ long model pipeline was assembled from two $2 \mathrm{~m}$ long clear Perspex pipe sections with identical external diameters. To reduce the amount of pipeline structural deflection, the pipeline was supported at both ends and the centre of the $4 \mathrm{~m}$ model pipeline, and the rigidity of the model pipeline was improved by increasing pipe wall thickness to $8.0 \mathrm{~mm}$. A schematic graph showing the model pipe cross section is given in Fig. 2. The Perspex pipes were cut into halves to allow the installation of the conductivity probes. A total of 30 pairs of $80 \mathrm{~mm}$ long stainless steel conductivity probes were installed at an interval of $120 \mathrm{~mm}$ along the pipeline to monitor the real time development of scour as shown in Fig. 3. After installing the conductivity probes, the pipe was backfilled with epoxy to insulate the electrical circuit from water and also to increase the pipeline's density and stiffness. The two halves of the pipe were glued back together with a smooth finish as shown in Fig. 4. For tests where flow was oblique to the model pipe, the $4 \mathrm{~m}$ model pipe was extended to the flume walls by connecting two equal length dummy model pipes of the same diameter as the model pipe at either end of the model pipe. No scour probes were installed on the dummy pipe sections.

A simple levelling device, previously used in Cheng et al. (2009), was used to ensure consistent embedment depth along the full length of the model pipeline. A small hole (also called worm hole) was dug underneath the model pipe at the middle section of the pipeline to allow scour propagation in both directions towards the flume walls. An acoustic Doppler velocimeter (ADV) was placed at an upstream location of the pipeline to measure the average flow velocities at 25 $\mathrm{mm}$ (about $50 \%$ of model pipe diameter) above the bed, while a wave probe was placed at $2.0 \mathrm{~m}$ upstream of the model pipe. Siliceous sands with $\mathrm{d}_{50}=0.37 \mathrm{~mm}$ and a specific gravity of 2.70 (particle size distribution presented in Fig. 5) were used in the experiments.

\section{Experimental results}

\subsection{Wave only conditions}

The focus of the testing programmes was to investigate the influence of the initial pipeline embedment depth, $\mathrm{KC}$ number and flow incident angle on the scour propagation rate along a rigid pipeline. The scour propagation velocity $\left(\mathrm{V}_{\mathrm{h}}\right)$ along the pipeline was obtained by analysing the time dependent scour depths of each individual probe installed on the model pipeline in the same manner as that reported by Cheng et al. (2009).

A total of 60 tests were conducted under wave only conditions, with the $\mathrm{KC}$ number ranging from 8.7 to 18.0 and the initial pipeline embedment depth varying from $0.1 \mathrm{D}$ to $0.5 \mathrm{D}$. Flow incident angle $\alpha$ relative to the pipeline ranged from $0^{\circ}$ to $45^{\circ}$. The test cases and test conditions are detailed in Table 1 . The wave orbital velocity was measured at $0.025 \mathrm{~m}$ above the original bed upstream of the model pipe using the ADV. It should be noted that the wave orbital velocity

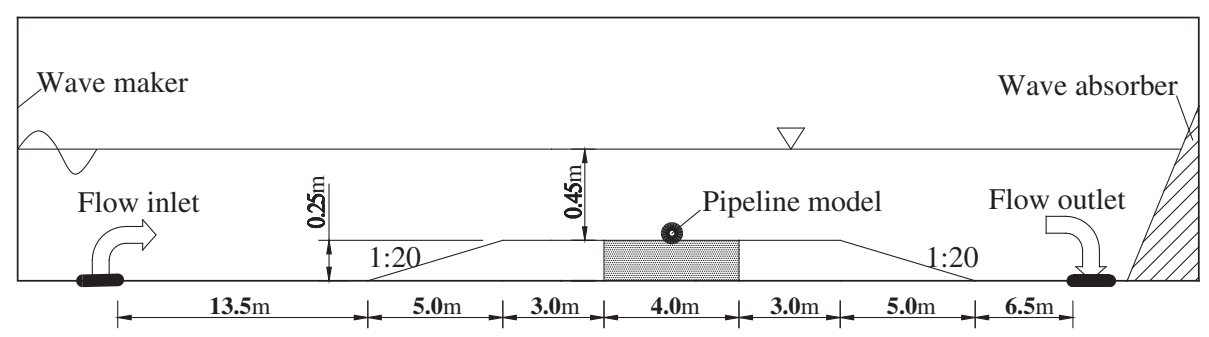

Fig. 1. Experimental setup. 




Fig. 2. A typical cross section of the model pipe.

amplitude $U_{w}$ shown in Table 1 was the average of the forward and reverse velocity amplitudes. The measured forward orbital velocity amplitudes were about 3\% to 13\% (normalized using the forward velocity amplitude) larger than the reverse orbital velocity amplitudes. The difference between the forward and reverse wave orbital velocity amplitudes appeared to increase with wave period as shown in Fig. 6.

The analysis results for wave only conditions are shown in Table 2. The Shields parameter shown in Table 2 was estimated using the following formulation suggested by Soulsby (1997).

$$
\theta_{w}=\frac{\tau_{w}}{\rho g\left(\rho_{s} / \rho-1\right) d_{50}}
$$

where $\tau_{\mathrm{w}}$ is wave-induced shear stress on the seabed, $\rho$ is density of water (taken as $1000 \mathrm{~kg} / \mathrm{m}^{3}$ ), $\rho_{\mathrm{s}}$ is density of sediment grains and $\mathrm{d}_{50}$ is the median grain size of the sediment. Wave induced shear stress on the seabed is estimated based on the following formula (Souslby, 1997).

$\tau_{\mathrm{w}}=\frac{1}{2} \rho \mathrm{f}_{\mathrm{w}} \mathrm{U}_{\mathrm{w}}^{2}$

$\mathrm{U}_{\mathrm{w}}$ is wave orbital velocity at the seabed (approximately taken as the measured velocity at $25 \mathrm{~mm}$ above the bed in this study), $\mathrm{f}_{\mathrm{w}}$ is the wave friction factor and is estimated using a formula suggested by Soulsby (1997).

$\mathrm{f}_{\mathrm{w}}=0.237 \mathrm{r}^{-0.52}$

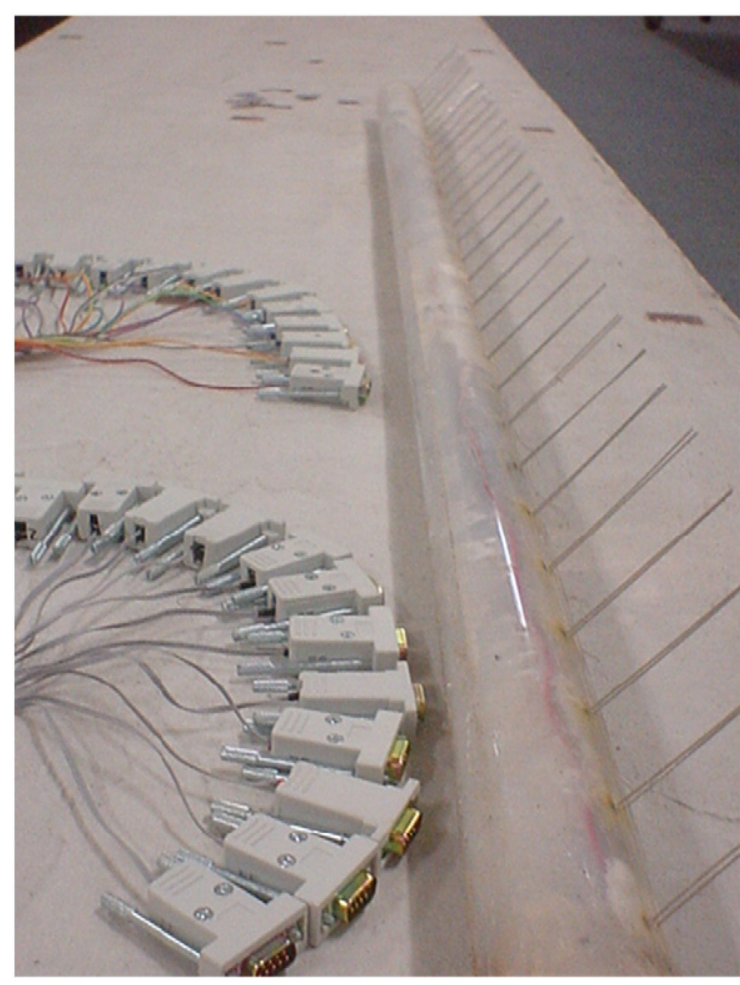

Fig. 4. A photograph of the $4 \mathrm{~m}$ model pipe.

$r=\frac{U_{w} T}{2 \pi k_{s}}$

Where $T$ is wave period and $k_{s}$ is Nikuradse equivalent sand grain roughness (taken as $k_{s}=2.5 d_{50}$ ). The critical Shields parameter for motion of the sediments used in the present study was 0.037 , estimated based on the method suggested by Soulsby (1997). All the tests were conducted under live bed conditions.

Temporal development of scour along the pipe was examined by analysing the scour depths measured by each individual scour probes installed on the model pipe. It was found, similar to what was observed in current only tests (Cheng et al., 2009), local scour propagated from the middle section of the pipeline towards either end of the pipeline once scour was initiated at the centre location of the pipeline. One common feature observed in all the wave only tests was that local scour propagated along the pipeline at a constant rate. This was somewhat different from the two-stage propagation rates observed under steady current conditions (Cheng et al., 2009, Wu and Chiew, 2012). Fig. 7 shows two typical measured time variations of free span length $S_{R}$ and $S_{L}$ measured in Test No. w15t15e3 (e/D = 0.3 ,

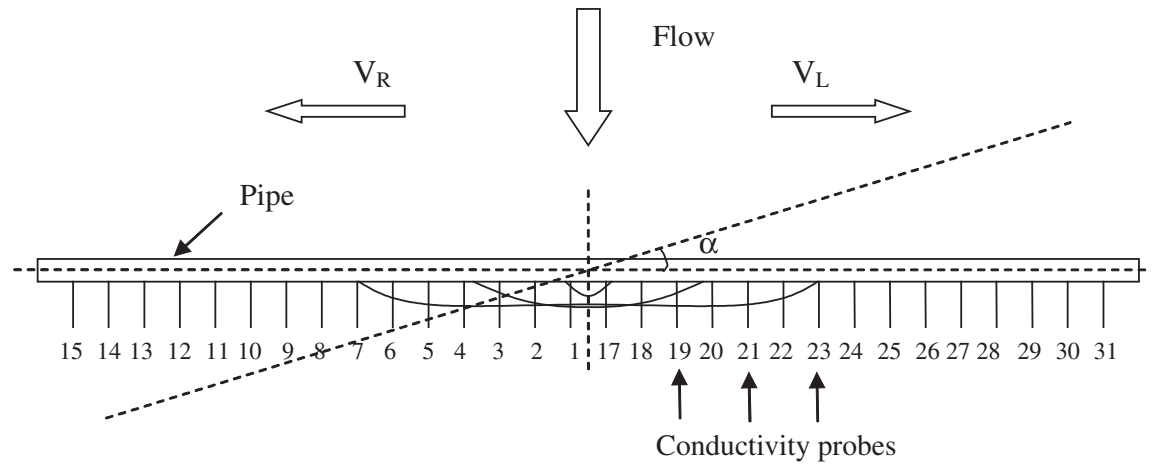

Fig. 3. An illustration sketch of the test setup. 


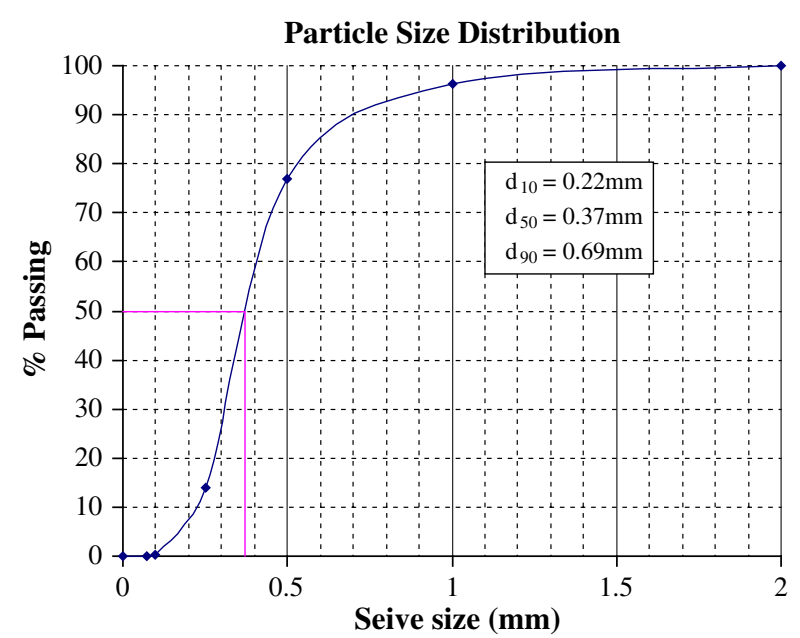

Fig. 5. Particle size distribution of sand used experiments.

$\mathrm{KC}=7.65$ and $\alpha=0^{\circ}$ ), where $\mathrm{S}_{\mathrm{R}}$ and $\mathrm{S}_{\mathrm{L}}$ are the right and left span lengths measured from the centre of the model pipe to the intersection of pipeline and seabed respectively (facing wave propagation direction). One possible reason that the two-stage scour propagation rates were not observed might be due to the limited range of the $\mathrm{KC}$ number and Shields parameter covered in this study. Cheng et al. (2009) suggested that the primary scour propagation rate (or the fast development rate defined by Wu and Chiew et al., 2012) observed in their study was due to three-dimensionality of the flow through the scour hole at initial stage of scour development. Another possible reason would have been that the spatial resolution of scour probes in those tests was not fine enough to capture the primary scour propagation rate under the present test conditions. The observed one-stage scour propagation characteristics, nevertheless, suggested that local scour was dominated by the flow through the narrow gaps between the pipeline and the sediment bed at two pipeline span shoulder regions under the present test conditions and test setup.

Effect of pipeline initial embedment depth and $\mathrm{KC}$ number on scour propagation along the pipeline was also investigated. Fig. 8 shows the variations of normalized scour propagation velocity $\mathrm{V}_{\mathrm{h}}{ }^{*}\left(\mathrm{~V}_{\mathrm{R}}{ }^{*}\right.$ and $\mathrm{V}_{\mathrm{L}}{ }^{*}$ are the normalized scour velocities at the right- and left-hand shoulders respectively and $V_{h}{ }^{*}$ denotes for the average of $V_{R}{ }^{*}$ and $V_{L}{ }^{*}$ ) with initial embedment depth at different $\mathrm{KC}$ values for test results with a $0^{\circ}$ flow approach angle (flow normal to the model pipeline). The normalized scour propagation velocity is expressed as below:

$\mathrm{V}_{\mathrm{h}}^{*}=\mathrm{V}_{\mathrm{h}} /\left(\sqrt{\mathrm{g}\left(\rho_{\mathrm{s}}-\rho\right) \mathrm{d}_{50}^{3} /(\mathrm{D} \tan \phi)}\right)$

The normalization method used in Eq. (5) can be derived from normalizing the sediment budget conservation equation as suggested by Sumer and Fredsøe (2002). Similar to the definition for the time scale used for local scour below a pipeline (Sumer and Fredsøe, 2002), the denominator of Eq. (5) simply represents the scale for scour rate. It can be seen that the scour propagation rates along the pipeline decrease almost linearly with the increase of initial embedment depth for all three KC number investigated. This is mainly because when the embedment depth increases, flow passing through the gap between the model pipe and the sediment bed at span shoulders decreases, resulting in a reduction of erosion power. The decrease in erosion power leads to the decrease of scour propagation velocity.

Fig. 9 shows the variations of normalized scour propagation velocity with $\mathrm{KC}$ at different initial embedment depths for test results with a $0^{\circ}$ flow approach angle. The data showed reasonably good correlation between scour propagation rates with KC at different initial embedment depths. The scour propagation rate increases with $\mathrm{KC}$ for all embedment
Table 1

Test conditions for wave only tests.

\begin{tabular}{|c|c|c|c|c|c|c|}
\hline Test number & $\alpha$, wave angle & $\mathrm{e} / \mathrm{D}$ & $\frac{\mathrm{H}}{\mathrm{m}}$ & $\frac{\mathrm{T}}{\mathrm{s}}$ & $\frac{\mathrm{U}_{\mathrm{w}}}{\mathrm{m} / \mathrm{s}}$ & KC \\
\hline w15t15e1 & $0^{\circ}$ & 0.1 & 0.13 & 1.5 & 0.29 & 8.7 \\
\hline w15t15e2 & $0^{\circ}$ & 0.2 & 0.13 & 1.5 & 0.29 & 8.7 \\
\hline w15t15e3 & $0^{\circ}$ & 0.3 & 0.13 & 1.5 & 0.29 & 8.7 \\
\hline w15t15e4 & $0^{\circ}$ & 0.4 & 0.13 & 1.5 & 0.29 & 8.7 \\
\hline w15t15e5 & $0^{\circ}$ & 0.5 & 0.13 & 1.5 & 0.29 & 8.7 \\
\hline w16t18e1 & $0^{\circ}$ & 0.1 & 0.17 & 1.8 & 0.44 & 15.8 \\
\hline w16t18e2 & $0^{\circ}$ & 0.2 & 0.17 & 1.8 & 0.44 & 15.8 \\
\hline w16t18e3 & $0^{\circ}$ & 0.3 & 0.17 & 1.8 & 0.44 & 15.8 \\
\hline w16t18e4 & $0^{\circ}$ & 0.4 & 0.17 & 1.8 & 0.44 & 15.8 \\
\hline w16t18e5 & $0^{\circ}$ & 0.5 & 0.17 & 1.8 & 0.44 & 15.8 \\
\hline w16t20e1 & $0^{\circ}$ & 0.1 & 0.15 & 2.0 & 0.45 & 18.0 \\
\hline w16t20e2 & $0^{\circ}$ & 0.2 & 0.15 & 2.0 & 0.45 & 18.0 \\
\hline w16t20e3 & $0^{\circ}$ & 0.3 & 0.15 & 2.0 & 0.45 & 18.0 \\
\hline w16t20e4 & $0^{\circ}$ & 0.4 & 0.15 & 2.0 & 0.45 & 18.0 \\
\hline w16t20e5 & $0^{\circ}$ & 0.5 & 0.15 & 2.0 & 0.45 & 18.0 \\
\hline a15w15t15e1 & $15^{\circ}$ & 0.1 & 0.13 & 1.5 & 0.29 & 8.7 \\
\hline a15w15t15e2 & $15^{\circ}$ & 0.2 & 0.13 & 1.5 & 0.29 & 8.7 \\
\hline a15w15t15e3 & $15^{\circ}$ & 0.3 & 0.13 & 1.5 & 0.29 & 8.7 \\
\hline a15w15t15e4 & $15^{\circ}$ & 0.4 & 0.13 & 1.5 & 0.29 & 8.7 \\
\hline a15w15t15e5 & $15^{\circ}$ & 0.5 & 0.13 & 1.5 & 0.29 & 8.7 \\
\hline a15w16t18e1 & $15^{\circ}$ & 0.1 & 0.17 & 1.8 & 0.44 & 15.8 \\
\hline a15w16t18e2 & $15^{\circ}$ & 0.2 & 0.17 & 1.8 & 0.44 & 15.8 \\
\hline a15w16t18e3 & $15^{\circ}$ & 0.3 & 0.17 & 1.8 & 0.44 & 15.8 \\
\hline a15w16t18e4 & $15^{\circ}$ & 0.4 & 0.17 & 1.8 & 0.44 & 15.8 \\
\hline a15w16t18e5 & $15^{\circ}$ & 0.5 & 0.17 & 1.8 & 0.44 & 15.8 \\
\hline a15w16t20e1 & $15^{\circ}$ & 0.1 & 0.15 & 2.0 & 0.45 & 18.0 \\
\hline a15w16t20e2 & $15^{\circ}$ & 0.2 & 0.15 & 2.0 & 0.45 & 18.0 \\
\hline a15w16t20e3 & $15^{\circ}$ & 0.3 & 0.15 & 2.0 & 0.45 & 18.0 \\
\hline a15w16t20e4 & $15^{\circ}$ & 0.4 & 0.15 & 2.0 & 0.45 & 18.0 \\
\hline a15w16t20e5 & $15^{\circ}$ & 0.5 & 0.15 & 2.0 & 0.45 & 18.0 \\
\hline a30w15t15e1 & $30^{\circ}$ & 0.1 & 0.13 & 1.5 & 0.29 & 8.7 \\
\hline a30w15t15e2 & $30^{\circ}$ & 0.2 & 0.13 & 1.5 & 0.29 & 8.7 \\
\hline a30w15t15e3 & $30^{\circ}$ & 0.3 & 0.13 & 1.5 & 0.29 & 8.7 \\
\hline a30w15t15e4 & $30^{\circ}$ & 0.4 & 0.13 & 1.5 & 0.29 & 8.7 \\
\hline a30w15t15e5 & $30^{\circ}$ & 0.5 & 0.13 & 1.5 & 0.29 & 8.7 \\
\hline a30w16t18e1 & $30^{\circ}$ & 0.1 & 0.17 & 1.8 & 0.44 & 15.8 \\
\hline a30w16t18e2 & $30^{\circ}$ & 0.2 & 0.17 & 1.8 & 0.44 & 15.8 \\
\hline a30w16t18e3 & $30^{\circ}$ & 0.3 & 0.17 & 1.8 & 0.44 & 15.8 \\
\hline a30w16t18e4 & $30^{\circ}$ & 0.4 & 0.17 & 1.8 & 0.44 & 15.8 \\
\hline a30w16t18e5 & $30^{\circ}$ & 0.5 & 0.17 & 1.8 & 0.44 & 15.8 \\
\hline a30w16t20e1 & $30^{\circ}$ & 0.1 & 0.15 & 2.0 & 0.45 & 18.0 \\
\hline a30w16t20e2 & $30^{\circ}$ & 0.2 & 0.15 & 2.0 & 0.45 & 18.0 \\
\hline a30w16t20e3 & $30^{\circ}$ & 0.3 & 0.15 & 2.0 & 0.45 & 18.0 \\
\hline a30w16t20e4 & $30^{\circ}$ & 0.4 & 0.15 & 2.0 & 0.45 & 18.0 \\
\hline a30w16t20e5 & $30^{\circ}$ & 0.5 & 0.15 & 2.0 & 0.45 & 18.0 \\
\hline a45w15t15e1 & $45^{\circ}$ & 0.1 & 0.13 & 1.5 & 0.29 & 8.7 \\
\hline $\mathrm{a} 45 \mathrm{w} 15 \mathrm{t} 15 \mathrm{e} 2$ & $45^{\circ}$ & 0.2 & 0.13 & 1.5 & 0.29 & 8.7 \\
\hline a $45 w 15 t 15 e 3$ & $45^{\circ}$ & 0.3 & 0.13 & 1.5 & 0.29 & 8.7 \\
\hline a 45w15t15e4 & $45^{\circ}$ & 0.4 & 0.13 & 1.5 & 0.29 & 8.7 \\
\hline a $45 w 15 t 15 e 5$ & $45^{\circ}$ & 0.5 & 0.13 & 1.5 & 0.29 & 8.7 \\
\hline a45w16t18e1 & $45^{\circ}$ & 0.1 & 0.17 & 1.8 & 0.44 & 15.8 \\
\hline $\mathrm{a} 45 \mathrm{w} 16 \mathrm{t} 18 \mathrm{e} 2$ & $45^{\circ}$ & 0.2 & 0.17 & 1.8 & 0.44 & 15.8 \\
\hline a45w16t18e3 & $45^{\circ}$ & 0.3 & 0.17 & 1.8 & 0.44 & 15.8 \\
\hline $\mathrm{a} 45 \mathrm{w} 16 \mathrm{t} 18 \mathrm{e} 4$ & $45^{\circ}$ & 0.4 & 0.17 & 1.8 & 0.44 & 15.8 \\
\hline a45w16t18e5 & $45^{\circ}$ & 0.5 & 0.17 & 1.8 & 0.44 & 15.8 \\
\hline a45w16t20e1 & $45^{\circ}$ & 0.1 & 0.15 & 2.0 & 0.45 & 18.0 \\
\hline $\mathrm{a} 45 \mathrm{w} 16 \mathrm{t} 20 \mathrm{e} 2$ & $45^{\circ}$ & 0.2 & 0.15 & 2.0 & 0.45 & 18.0 \\
\hline a $45 w 16 t 20 e 3$ & $45^{\circ}$ & 0.3 & 0.15 & 2.0 & 0.45 & 18.0 \\
\hline $\mathrm{a} 45 \mathrm{w} 16 \mathrm{t} 20 \mathrm{e} 4$ & $45^{\circ}$ & 0.4 & 0.15 & 2.0 & 0.45 & 18.0 \\
\hline a $45 w 16 t 20 e 5$ & $45^{\circ}$ & 0.5 & 0.15 & 2.0 & 0.45 & 18.0 \\
\hline
\end{tabular}

tested in this study in a similar way to the two-dimensional scour depth increase with KC reported by Sumer and Fredsøe (2002). The physics behind the two-dimensional scour depth increase with $\mathrm{KC}$ was well explained in Sumer and Fredsøe (2002). A similar explanation is also provided here. When the KC number increases, the sediment bed area exposed to the disturbed flow around model pipe also increases. It is well known that vortex shedding takes place around the model pipe when the KC number is greater than 6 (Sumer and Fredsøe, 2002). The combination of a larger exposed area for scour and the strong 


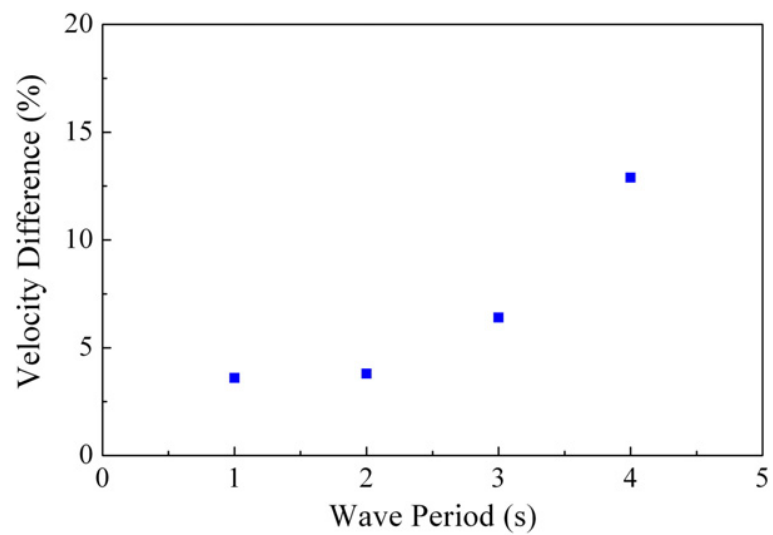

Fig. 6. Relative difference between forward and reverse wave orbital velocity amplitudes, normalized using the forward velocity amplitudes.

interaction between vortices shed from the model pipe and the sediment bed leads to a gentle slope of the scour hole either side of the model pipe, allowing more flow passing through the gap between the model pipe and the sediment bed. The increase of the flow through the gap between the model pipe and the sediment bed in turn causes the increase in scour propagation velocity observed in Fig. 9. It should be noted that the variations shown in Fig. 10 are also inclusive of the influence of the Shields parameter. The corresponding Shields parameter for $\mathrm{KC}=8.7,15.8$ and 18.0 in the present study are 018 , 0.30 and 0.29 , respectively. It appears that the scour propagation rate also increases with the increase of the Shields parameter. This is consistent with the observations in two dimensional scour tests that time scale of scour decreases and scour rate increases with the Shields parameter under wave only conditions (Sumer and Fredsøe, 2002). This is because the sediment transport rate normally increases with the Shields parameter, resulting in a shorter time period required for the same amount of scour at a large Shields parameter than at a small Shields parameter (Sumer and Fredsøe, 2002).

The effect of the flow attack angle $(\alpha)$ on the scour propagation along the pipe was investigated by installing the model pipe obliquely to the wave propagation direction. The flow incidence angles examined in the tests were $\alpha=0^{\circ}, 15^{\circ}, 30^{\circ}$ and $45^{\circ}$. Figs. 10 to 12 show the variations of the scour propagation rate with the attack angle of the wave induced flow. The test results presented in Figs. 10 to 12 showed that scour propagation rates along the pipeline decreased with flow angle of attack over the ranges of the pipeline initial embedment depth and KC number. The reduction of scour propagation rates due to the flow oblique angle was up to approximately $60 \%$ when $\alpha=45^{\circ}$, compared with those at a $0^{\circ}$ flow attack angle. Similar to the findings by Cheng et al. (2009) in the current only condition, it is believed that the net flow perpendicular to the pipeline was principally responsible for the scour propagation along the pipeline. When the flow angle of attack $(\alpha)$ was increased, the velocity component perpendicular to the pipeline reduced which resulted in the reduction of the scour propagation rates along the pipeline.

One of the interesting phenomena found in the present study was that the scour propagation rates at two span shoulders of the free span were almost independent on the flow attack angle under wave only conditions, unlike the cases under currents only conditions (Cheng et al., 2009) where the scour propagation rate at the downstream span shoulder side (relative to flow direction) is noticeably faster than the propagation at the upstream span shoulder side $\left(V_{R}>V_{L}\right.$, refer to Fig. 3). This was due to the bi-directional orbital velocities induced by waves. When a wave crest was passing through over the pipeline location, it generated a forward orbital velocity, resulting in a faster propagation rate at the downstream span shoulder side of the free span. The opposite happened when a wave trough was passing
Table 2

Experimental results on scour propagation for wave only conditions.

\begin{tabular}{|c|c|c|c|c|c|c|}
\hline \multirow[t]{2}{*}{ Test number } & \multirow[t]{2}{*}{ KC } & \multirow[t]{2}{*}{$\theta_{\mathrm{w}}$} & \multirow{2}{*}{$\frac{\mathrm{V}_{\mathrm{R}}}{\mathrm{mm} / \mathrm{s}}$} & \multirow{2}{*}{$\frac{\mathrm{V}_{\mathrm{L}}}{\mathrm{mm} / \mathrm{s}}$} & \multirow{2}{*}{$\frac{\mathrm{V}_{\mathrm{h}}}{\mathrm{mm} / \mathrm{s}}$} & \multirow{2}{*}{$\frac{\text { Eq. (8) }}{\mathrm{mm} / \mathrm{s}}$} \\
\hline & & & & & & \\
\hline w15t15e1 & 8.7 & 0.18 & 3.4 & 3.6 & 3.5 & 1.5 \\
\hline w15t15e2 & 8.7 & 0.18 & 2.8 & 4.8 & 3.8 & 1.4 \\
\hline w15t15e3 & 8.7 & 0.18 & 2.6 & 2.6 & 2.6 & 1.2 \\
\hline w15t15e4 & 8.7 & 0.18 & 1.8 & 2.0 & 1.9 & 1.0 \\
\hline w15t15e5 & 8.7 & 0.18 & \multicolumn{4}{|c|}{ No scour propagation observed } \\
\hline w16t18e1 & 15.8 & 0.30 & 5.1 & 6.3 & 5.7 & 4.9 \\
\hline w16t18e2 & 15.8 & 0.30 & 4.4 & 5.4 & 4.9 & 4.4 \\
\hline w16t18e3 & 15.8 & 0.30 & 4.0 & 4.6 & 4.3 & 3.8 \\
\hline w16t18e4 & 15.8 & 0.30 & 2.8 & 3.7 & 3.2 & 3.3 \\
\hline w16t18e5 & 15.8 & 0.30 & \multicolumn{4}{|c|}{ No scour propagation observed } \\
\hline w16t20e1 & 18.0 & 0.29 & 5.7 & 6.5 & 6.1 & 5.1 \\
\hline w16t20e2 & 18.0 & 0.29 & 5.5 & 5.3 & 5.4 & 4.5 \\
\hline w16t20e3 & 18.0 & 0.29 & 4.7 & 4.7 & 4.7 & 3.9 \\
\hline w16t20e4 & 18.0 & 0.29 & 3.7 & 3.0 & 3.4 & 3.4 \\
\hline w16t20e5 & 18.0 & 0.29 & \multicolumn{4}{|c|}{ No scour propagation observed } \\
\hline a15w15t15e1 & 8.7 & 0.18 & \multicolumn{4}{|c|}{ Onset of scour multiple locations } \\
\hline a15w15t15e2 & 8.7 & 0.18 & \multicolumn{4}{|c|}{ Onset of scour multiple locations } \\
\hline a15w15t15e3 & 8.7 & 0.18 & 2.7 & 1.6 & 2.2 & 1.1 \\
\hline a15w15t15e4 & 8.7 & 0.18 & 1.5 & 1.6 & 1.5 & 0.8 \\
\hline a15w15t15e5 & 8.7 & 0.18 & \multicolumn{4}{|c|}{ No scour propagation observed } \\
\hline a15w16t18e1 & 15.8 & 0.30 & 5.6 & 5.2 & 5.4 & 4.8 \\
\hline a15w16t18e2 & 15.8 & 0.30 & 4.5 & 4.1 & 4.3 & 4.1 \\
\hline a15w16t18e3 & 15.8 & 0.30 & 4.4 & 4.0 & 4.2 & 3.4 \\
\hline a15w16t18e4 & 15.8 & 0.30 & 3.1 & 2.6 & 2.8 & 2.7 \\
\hline a15w16t18e5 & 15.8 & 0.30 & \multicolumn{4}{|c|}{ No scour propagation observed } \\
\hline a15w16t20e1 & 18.0 & 0.29 & \multicolumn{4}{|c|}{ Onset of scour multiple locations } \\
\hline a15w16t20e2 & 18.0 & 0.29 & 5.2 & 4.4 & 4.8 & 4.2 \\
\hline a15w16t20e3 & 18.0 & 0.29 & 4.3 & 3.7 & 4.0 & 3.5 \\
\hline a15w16t20e4 & 18.0 & 0.29 & 3.0 & 3.4 & 3.2 & 2.8 \\
\hline a15w16t20e5 & 18.0 & 0.29 & No scol & ropaga & bserved & \\
\hline a30w15t15e1 & 8.7 & 0.18 & 3.0 & 2.2 & 2.6 & 1.4 \\
\hline a30w15t15e2 & 8.7 & 0.18 & 1.4 & 2.2 & 1.8 & 1.2 \\
\hline a30w15t15e3 & 8.7 & 0.18 & 0.9 & N/A & 0.9 & 0.9 \\
\hline a30w15t15e4 & 8.7 & 0.18 & 0.9 & $\mathrm{~N} / \mathrm{A}$ & 0.9 & 0.7 \\
\hline a30w15t15e5 & 8.7 & 0.18 & No scol & ropaga & bserved & \\
\hline a30w16t18e1 & 15.8 & 0.30 & 4.0 & 3.9 & 3.9 & 4.6 \\
\hline a30w16t18e2 & 15.8 & 0.30 & 3.6 & 3.2 & 3.4 & 3.8 \\
\hline a30w16t18e3 & 15.8 & 0.30 & 3.1 & 2.7 & 2.9 & 3.0 \\
\hline a30w16t18e4 & 15.8 & 0.30 & 2.6 & 2.3 & 2.5 & 2.2 \\
\hline a30w16t18e5 & 15.8 & 0.30 & No scol & ropaga & bserved & \\
\hline a30w16t20e1 & 18.0 & 0.29 & 4.1 & 3.4 & 3.8 & 4.8 \\
\hline a30w16t20e2 & 18.0 & 0.29 & 3.4 & 3.1 & 3.2 & 3.9 \\
\hline a30w16t20e3 & 18.0 & 0.29 & 3.1 & 2.3 & 2.7 & 3.1 \\
\hline a30w16t20e4 & 18.0 & 0.29 & 2.3 & 2.3 & 2.3 & 2.2 \\
\hline a30w16t20e5 & 18.0 & 0.29 & No scol & ropaga & bserved & \\
\hline $\mathrm{a} 45 \mathrm{w} 15 \mathrm{t} 15 \mathrm{e} 1$ & 8.7 & 0.18 & 1.7 & 1.9 & 1.8 & 1.4 \\
\hline $\mathrm{a} 45 \mathrm{w} 15 \mathrm{t} 15 \mathrm{e} 2$ & 8.7 & 0.18 & 1.4 & 1.8 & 1.6 & 1.1 \\
\hline $\mathrm{a} 45 \mathrm{w} 15 \mathrm{t} 15 \mathrm{e} 3$ & 8.7 & 0.18 & No scol & ropaga & bserved & \\
\hline $\mathrm{a} 45 \mathrm{w} 15 \mathrm{t} 15 \mathrm{e} 4$ & 8.7 & 0.18 & No scol & ropaga & bserved & \\
\hline a $45 w 15 t 15 e 5$ & 8.7 & 0.18 & No scol & ropaga & bserved & \\
\hline $\mathrm{a} 45 \mathrm{w} 16 \mathrm{t} 18 \mathrm{e} 1$ & 15.8 & 0.30 & 2.7 & 2.8 & 2.7 & 4.5 \\
\hline a45w16t18e2 & 15.8 & 0.30 & 1.9 & 2.5 & 2.2 & 3.6 \\
\hline a 45w16t18e3 & 15.8 & 0.30 & 1.6 & 2.0 & 1.8 & 2.7 \\
\hline $\mathrm{a} 45 \mathrm{w} 16 \mathrm{t} 18 \mathrm{e} 4$ & 15.8 & 0.30 & No scol & ropaga & bserved & \\
\hline a45w16t18e5 & 15.8 & 0.30 & No scol & ropaga & bserved & \\
\hline $\mathrm{a} 45 \mathrm{w} 16 \mathrm{t} 20 \mathrm{e} 1$ & 18.0 & 0.29 & 3.1 & 2.4 & 2.8 & 4.7 \\
\hline $\mathrm{a} 45 \mathrm{w} 16 \mathrm{t} 20 \mathrm{e} 2$ & 18.0 & 0.29 & 2.3 & 2.3 & 2.3 & 3.7 \\
\hline a45w16t20e3 & 18.0 & 0.29 & 1.6 & $\mathrm{~N} / \mathrm{A}$ & 1.6 & 2.7 \\
\hline $\mathrm{a} 45 \mathrm{w} 16 \mathrm{t} 20 \mathrm{e} 4$ & 18.0 & 0.29 & No scol & ropaga & bserved & \\
\hline a $45 w 16 t 20 e 5$ & 18.0 & 0.29 & No scol & ropaga & bserved & \\
\hline
\end{tabular}

Note: N/A listed in the table denotes the tests where scour propagation was only observed on the upstream span shoulder. This was likely due to asymmetry of the wave orbital velocity. The measured reverse velocity was generally smaller than the forward velocity.

over the pipeline where a reverse flow was generated, resulting in $V_{R}$ $<\mathrm{V}_{\mathrm{L}}$ in the other half of a wave period. Since the forward orbital velocity was approximately the same, the net propagation rates at two span shoulders were almost identical.

Two other interesting phenomena were also observed in the tests. One was the onset of scour at multiple locations along the pipeline and the other was the backfill of the initial scour (worm) hole 


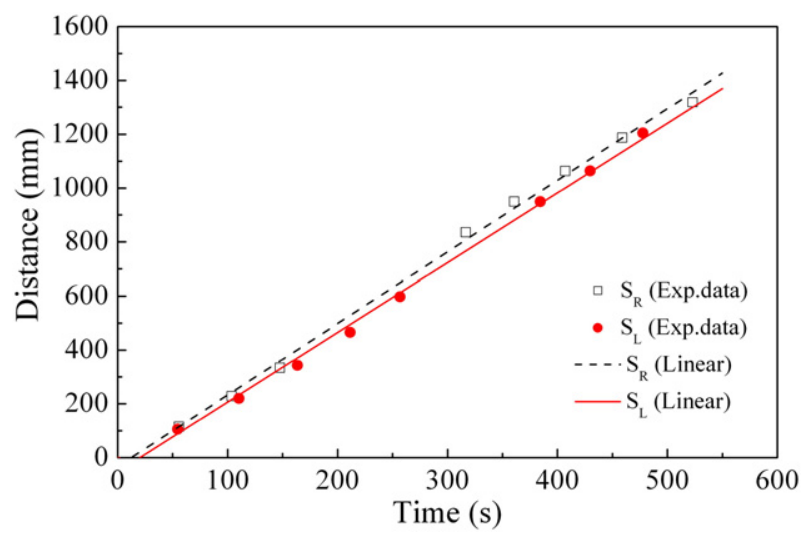

Fig. 7. Typical scour propagation lengths measured in Test $w 15 t 15 e 3(e / D=0.3, K C=8.7$ and $\alpha=0^{\circ}$ ), where $S_{R}$ and $S_{L}$ are the span lengths measured from the centre of the model pipe to the right and left sides of model pipe respectively (facing wave propagation direction). (a) Variations of normalized scour propagation rate with embedment depth at the right-hand span shoulder (flow incidence $\alpha=0^{\circ}$ ). (b) Variations of normalized scour propagation rate with embedment depth at the left-hand span shoulder (flow incidence $\alpha=0^{\circ}$ ).

deliberately created at the centre of the pipeline. The onset of scour at multiple locations was observed for three tests all with small initial embedment depths $(<0.2)$ as detailed in Table 3. It is believed that the onset of scour was induced by the piping mechanism (e.g. Sumer and Fredsøe, 2002; Zang et al., 2009). To confirm this, an onset parameter (OP) for those tests was compared with the onset criterion detailed in
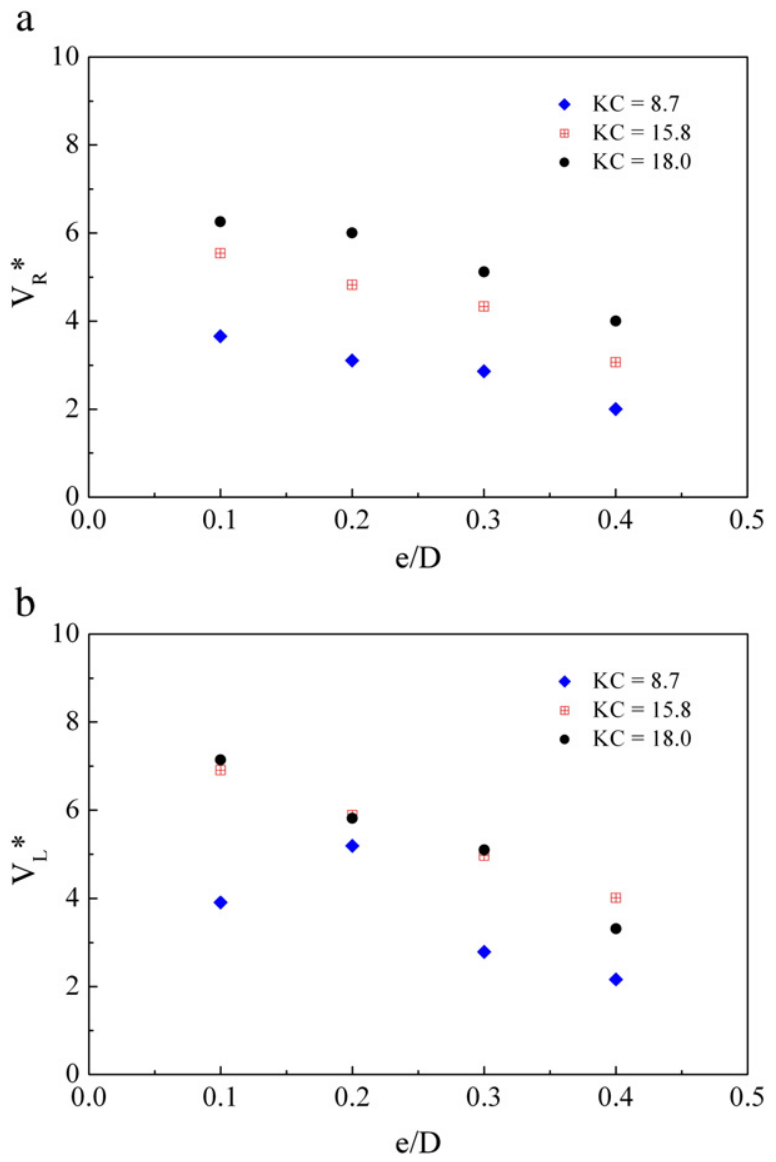

Fig. 8. Variations of normalized scour propagation rate with embedment depth. (a) Scour propagation rate at the right-hand span shoulder. (b) Scour propagation rate at the left-hand span shoulder.
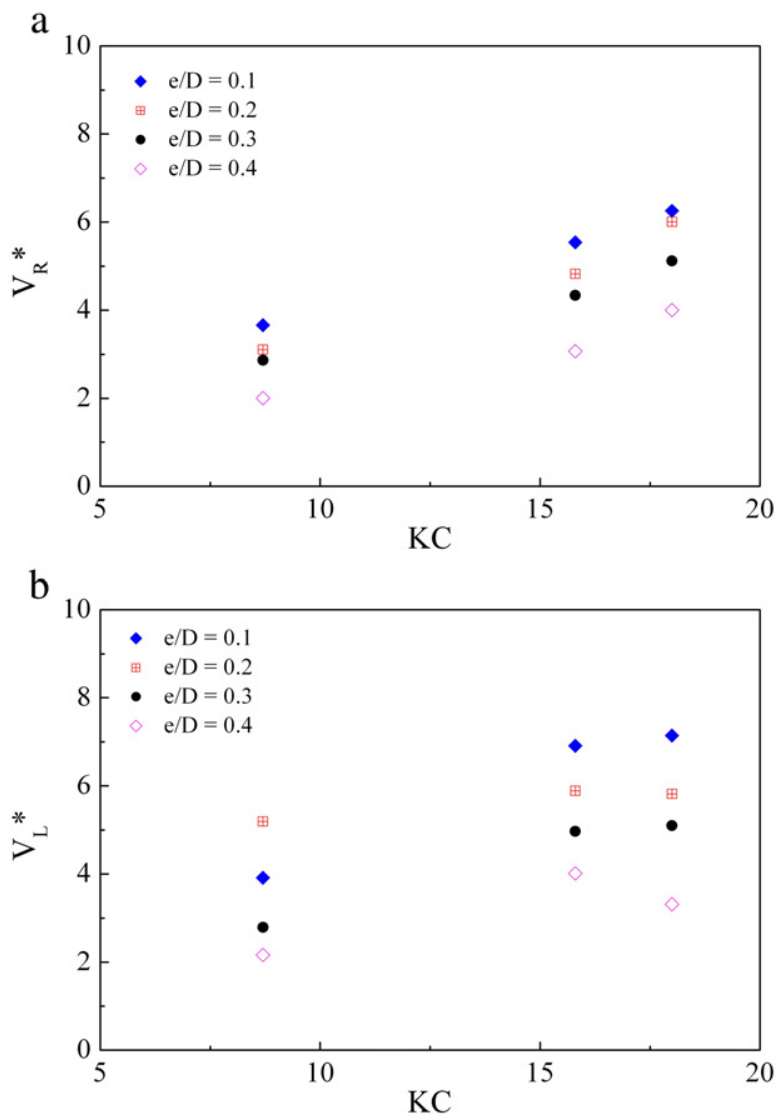

Fig. 9. Variations of normalized scour propagation rate with KC number, $\left(\alpha=0^{\circ}\right)$. (a) Scour propagation rate at the right-hand span shoulder. (b) Scour propagation rate at the left-hand span shoulder.

Sumer and Fredsøe (Fig. 2.8, page 24) in Table 3. The onset parameter is defined as

$\mathrm{OP}=\frac{\mathrm{U}_{\mathrm{w}}^{2}}{\mathrm{gD}\left(\rho_{\mathrm{s}} / \rho-1\right)(1-\mathrm{n})}$,

where $\mathrm{n}$ is the porosity of the sediment (taken as 0.4 ). The critical onset parameter listed in Table 3 was obtained by reading off the graph provided in Sumer and Fredsøe (2002). It is seen that the onset parameter OP for the three test cases listed in Table 3 were larger than the critical onset parameter, suggesting the likelihood of onset of scour by piping. It should be pointed out that the onset of scour criterion applied in the present study was indicative only because it was derived based on model tests where wave propagation direction was perpendicular to the pipeline. It is expected that the existence of the initial small worm hole at the central location of the pipeline would also affect the conditions for onset of scour. It should also be noted that the errors in achieving the desired initial embedment depths in the tests would also contribute to the onset of scour in these tests.

It was observed in a number of tests that the initial artificial scour hole in the middle of the pipeline was backfilled soon after the tests started and no scour propagation ever took place. This situation only occurred for the cases with large embedment depths as detailed in Table 4. It appeared that the backfill of the initial worm hole was dependent on the initial embedment depth, $\mathrm{KC}$ and orbital flow incidence angle. For small orbital flow incidence angles $\left(<30^{\circ}\right)$, the backfill occurred at e/D $=0.5$ regardless of KC. For the cases with a $45^{\circ}$ flow incidence angle, the critical initial embedment depth that backfill occurred appeared to be weakly dependent on KC. The critical initial embedment depths for backfill were $0.3,0.4$ and 0.5 at $\mathrm{KC}=8.7,15.8$ and 18.0 correspondingly. It indicates that the critical initial embedment 
a

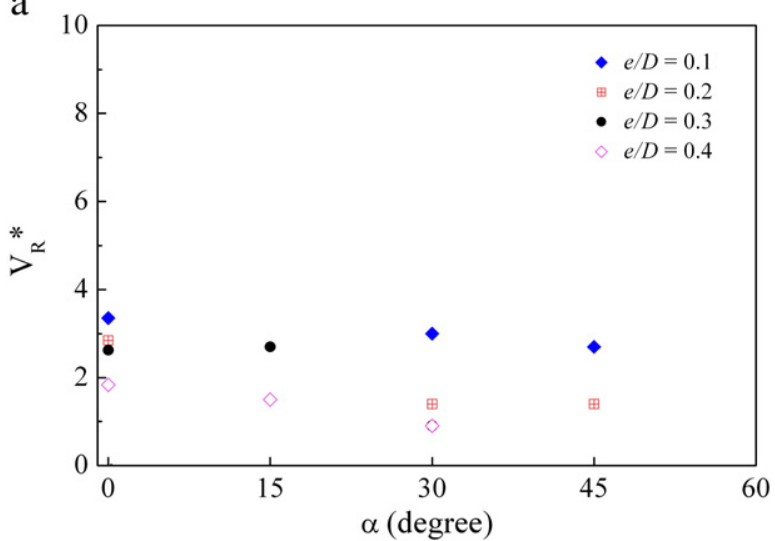

b

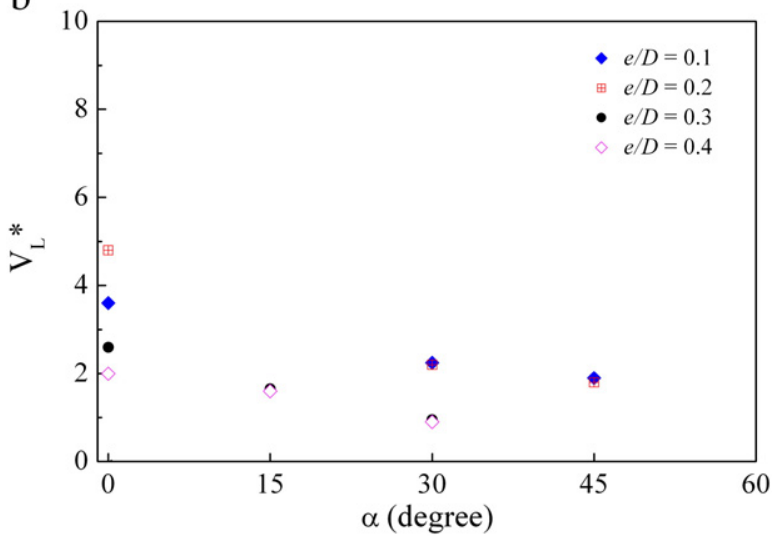

Fig. 10. Variation of normalized propagation rate with flow incidence $(K C=8.7)$. (a) Scour propagation rate at the right-hand span shoulder. (b) Scour propagation rate at the lefthand span shoulder.

depths for backfill reduced with the increase of orbital flow incidence angle. The limited test conditions (embedment, flow incidence angle and $\mathrm{KC}$ ) in the present study did not allow quantitative relationships between the critical embedment depth and those parameters being established.

\subsubsection{Prediction of scour propagation rate for wave only conditions}

A predictive model for scour propagation rates along a rigid, partially embedded pipeline under wave only conditions is proposed here. The derivation of the predictive model followed the same procedure proposed by Cheng et al. (2009) with minor modifications to accommodate for wave only conditions. Only one modification made to the method proposed by Cheng et al. (2009) was the method to calculate the two-dimensional equilibrium scour depth induced by waves. The formula suggested by Sumer and Fredsøe (2002) was employed to estimate the two-dimensional equilibrium scour depth induced by waves.

$\mathrm{S}_{0}=0.1 \mathrm{D} \sqrt{\mathrm{KC}}$

Following the same procedure as that proposed by Cheng et al. (2009), the following scour propagation rate along the pipeline was derived:

$\mathrm{V}_{\mathrm{h}}=\mathrm{K}_{\mathrm{w}}\left(1-\frac{\mathrm{e}}{\mathrm{D}}(1+\sin (\alpha))\right) \frac{\sqrt{\mathrm{g}\left(\rho_{\mathrm{s}} / \rho-1\right) \mathrm{d}_{50}^{3}}}{\mathrm{D} \tan \varphi} \theta_{\mathrm{w}}^{5 / 3} \sqrt{\mathrm{KC}}$

where $K_{w}$ is a constant to be obtained by calibrating against experimental data, $\phi$ is the angle of repose of the sediment and $\theta_{\mathrm{w}}$ is the wave Shields parameter.
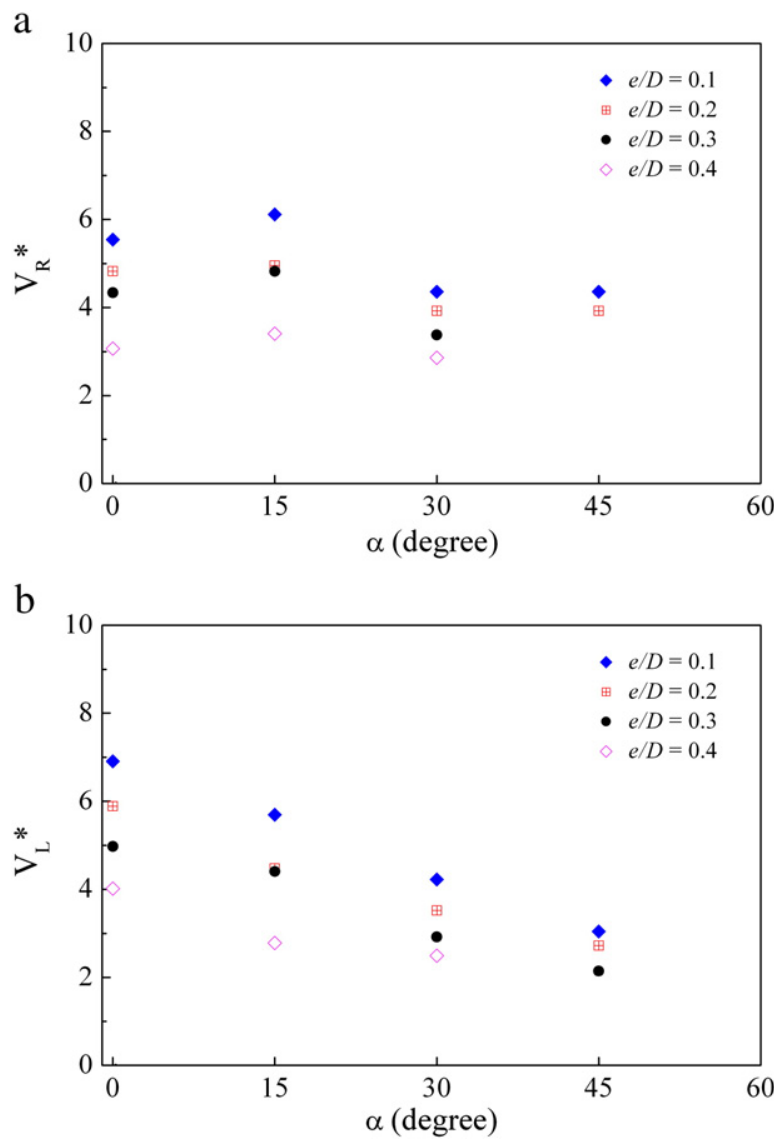

Fig. 11. Variation of normalized propagation rate with flow incidence ( $K C=15.8$ ). (a) Scour propagation rate at the right-hand span shoulder. (b) Scour propagation rate at the left-hand span shoulder.

The constant $\mathrm{K}_{\mathrm{w}}=11.3$ was obtained by calibrations against the average propagation rates listed in Table 2 using the least squares method. The predictions of scour propagation rate using Eq. (8) with $\mathrm{K}_{\mathrm{w}}=11.3$ were provided in the last column of Table 2 . The measured scour propagation rate and the predicted scour propagation rate using Eq. (8) for $\alpha=0^{\circ}$ and $\alpha=30^{\circ}$ are compared with the experimental data in Fig. 13-18. It was found that the predictions obtained using Eq. (8) showed reasonable overall comparisons with the experimental data over the range of parameters investigated in this study, although it under-predicted the scour propagation rates by about $50 \%-60 \%$ for tests with $\mathrm{KC}=8.7$ and $\alpha=0^{\circ}$ and over-predicted the rates for about $60 \%$ for tests with $\alpha=45^{\circ}$. The comparisons of measured scour propagation rate and predicted scour propagation rate using Eq. (8) for $\alpha=15^{\circ}$ and $\alpha=45^{\circ}$ are similar to those for $\alpha=0^{\circ}$ and $\alpha=30^{\circ}$ are not shown here but are detailed in Table 2 .

\subsection{Combined wave and current conditions}

Local scour propagations along pipelines were investigated under combined wave and current conditions. A total of 65 tests were conducted under combined wave and current conditions, with the KC number ranging from 2.0 to 12.0 , velocity ratio $\mathrm{m}\left(=\mathrm{U}_{\mathrm{c}} /\left(\mathrm{U}_{\mathrm{c}}+\mathrm{U}_{\mathrm{w}}\right)\right)$ ranging from 0.181 to 0.813 (excluding wave only and current only tests) and initial pipeline embedment depth varying from 0.1D to $0.5 \mathrm{D}$. Flow incident angle $\alpha$ relative to the pipeline was set at $0^{\circ}$. The model pipe and sediments used were identical to those used in wave only tests. The test cases and test conditions are detailed in Table 5. The combined velocity was measured at $0.025 \mathrm{~m}$ above the original bed upstream of the model pipe using the ADV. The steady current and orbital velocity were derived by analysing the velocity time series 
a

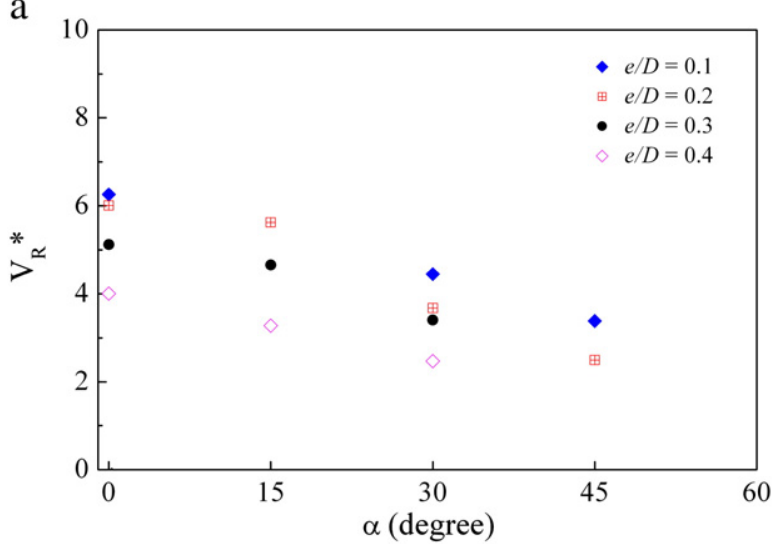

b

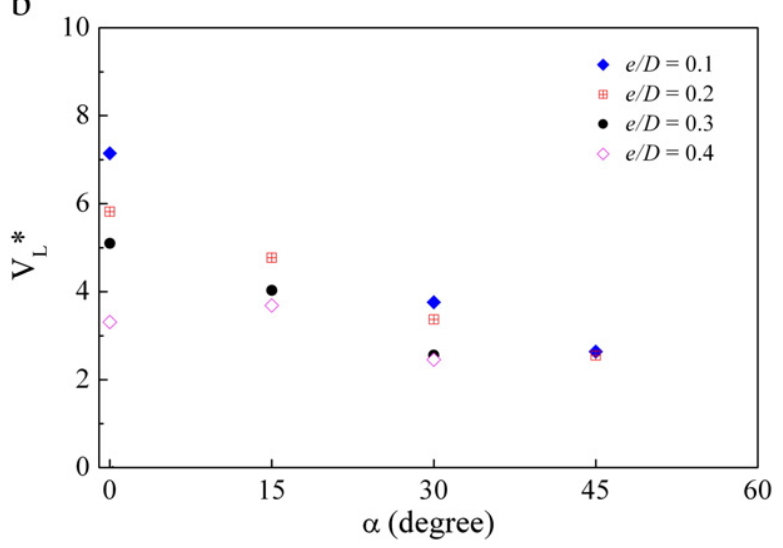

Fig. 12. Variation of normalized propagation rate with flow incidence $(K C=18.0)$.

recorded by ADV. The average of the forward and reverse orbital velocity amplitudes were used in the analysis below. The tests were conducted under live bed conditions. The maximum Shields parameter

Table 3

Test cases with onset of scour at multiple locations along the pipeline.

\begin{tabular}{|c|c|c|c|c|c|c|}
\hline \multirow[t]{2}{*}{ Test number } & \multirow[t]{2}{*}{$\alpha$, wave angle } & \multirow[t]{2}{*}{$\mathrm{e} / \mathrm{D}$} & $\mathrm{U}_{\mathrm{w}}$ & \multirow[t]{2}{*}{ KC } & \multirow{2}{*}{$\begin{array}{l}\text { Onset } \\
\text { Parameter OP }\end{array}$} & \multirow{2}{*}{$\begin{array}{l}\text { Critical Onset } \\
\text { Parameter }\end{array}$} \\
\hline & & & $\overline{(\mathrm{m} / \mathrm{s})}$ & & & \\
\hline a15w15t15e1 & $15.0^{\circ}$ & 0.1 & 0.29 & 8.7 & 0.17 & 0.11 \\
\hline a15w15t15e2 & $15.0^{\circ}$ & 0.2 & 0.29 & 8.7 & 0.17 & 0.16 \\
\hline a15w16t20e1 & $15.0^{\circ}$ & 0.1 & 0.45 & 18.0 & 0.42 & 0.15 \\
\hline
\end{tabular}

Table 4

Test cases with no scour propagation due the backfill of initial worm hole.

\begin{tabular}{lcllr}
\hline Test number & Wave angle $\alpha$ & $\mathrm{e} / \mathrm{D}$ & $\frac{\mathrm{U}_{\mathrm{w}}}{\mathrm{n}}$ & $\mathrm{KC}$ \\
& & & $(\mathrm{m} / \mathrm{s})$ & \\
\hline w15t15e5 & $0^{\circ}$ & 0.5 & 0.29 & 8.7 \\
w16t18e5 & $0^{\circ}$ & 0.5 & 0.44 & 15.8 \\
w16t20e5 & $0^{\circ}$ & 0.5 & 0.45 & 18.0 \\
a15w15t15e5 & $15^{\circ}$ & 0.5 & 0.29 & 8.7 \\
a15w16t18e5 & $15^{\circ}$ & 0.5 & 0.44 & 15.8 \\
a15w16t20e5 & $15^{\circ}$ & 0.5 & 0.45 & 18.0 \\
a30w15t15e5 & $30^{\circ}$ & 0.5 & 0.29 & 8.7 \\
a30w16t18e5 & $30^{\circ}$ & 0.5 & 0.44 & 15.8 \\
a30w16t20e5 & $30^{\circ}$ & 0.5 & 0.45 & 18.0 \\
a45w15t15e3 & $45^{\circ}$ & 0.3 & 0.29 & 8.7 \\
a45w15t15e4 & $45^{\circ}$ & 0.4 & 0.29 & 8.7 \\
a45w15t15e5 & $45^{\circ}$ & 0.5 & 0.29 & 8.7 \\
a45w16t18e4 & $45^{\circ}$ & 0.4 & 0.44 & 15.8 \\
a45w16t18e5 & $45^{\circ}$ & 0.5 & 0.44 & 15.8 \\
a45w16t20e4 & $45^{\circ}$ & 0.4 & 0.45 & 18.0 \\
a45w16t20e5 & $45^{\circ}$ & 0.5 & 0.45 & 18.0 \\
\hline
\end{tabular}

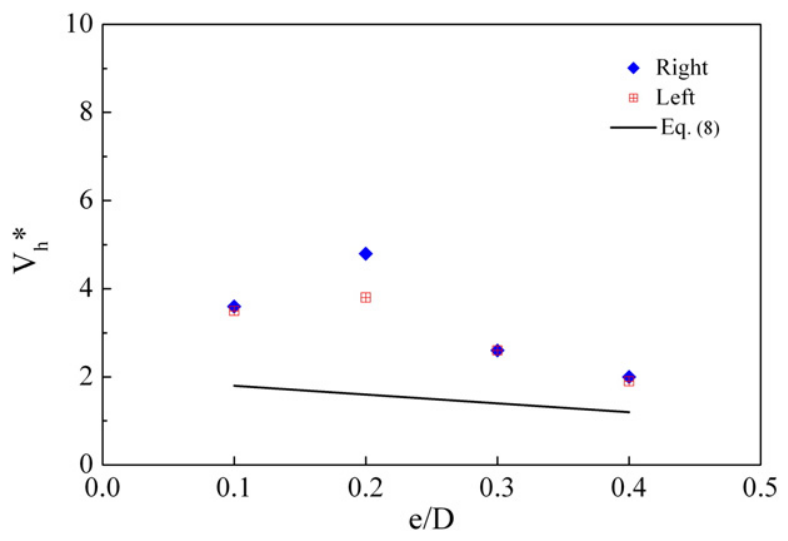

Fig. 13. Comparisons between experimental data and predictions $\left(\alpha=0^{\circ}, \mathrm{KC}=8.7\right)$.



Fig. 14. Comparisons between experimental data and predictions $\left(\alpha=0^{\circ}, \mathrm{KC}=15.8\right)$.

$\theta_{\mathrm{w}}$ shown in Table 6 was estimated using the "DATA2" method suggested by Soulsby (1997). The bed shear stress induced by steady current was estimated by assuming a logarithmic velocity profile in vertical direction and bed shear stress induced by waves was calculated using Eqs. (2) to (4). The bed roughness $z_{0}=d_{50} / 12$ was assumed in estimating the bed shear stresses.

The variations of the measured scour propagation rate with velocity ratio, $\mathrm{m}$, under combined wave and current conditions were listed in Table 6 and also plotted in Figs. 19 to 21. The measured scour propagation rates showed a general trend where the scour propagation firstly decreased as the current velocity was increased from zero. This phenomenon was similar to the variations of two-dimensional scour

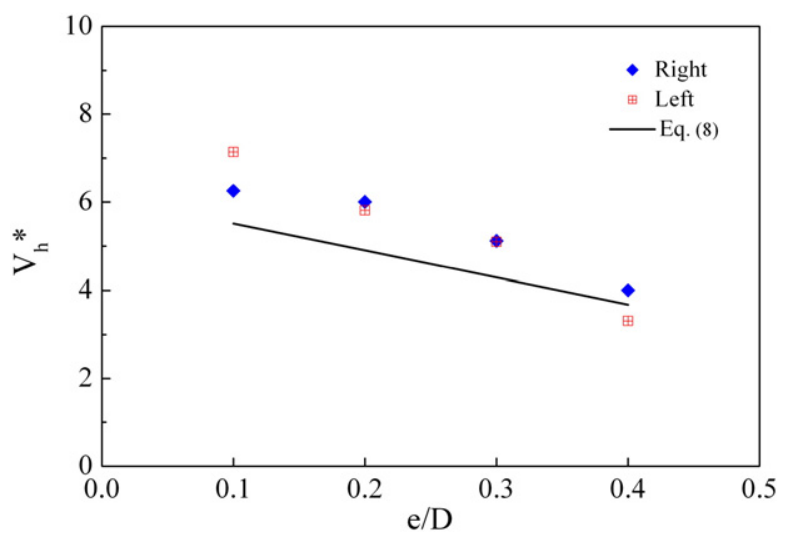

Fig. 15. Comparisons between experimental data and predictions $\left(\alpha=0^{\circ}, \mathrm{KC}=18.0\right)$. 


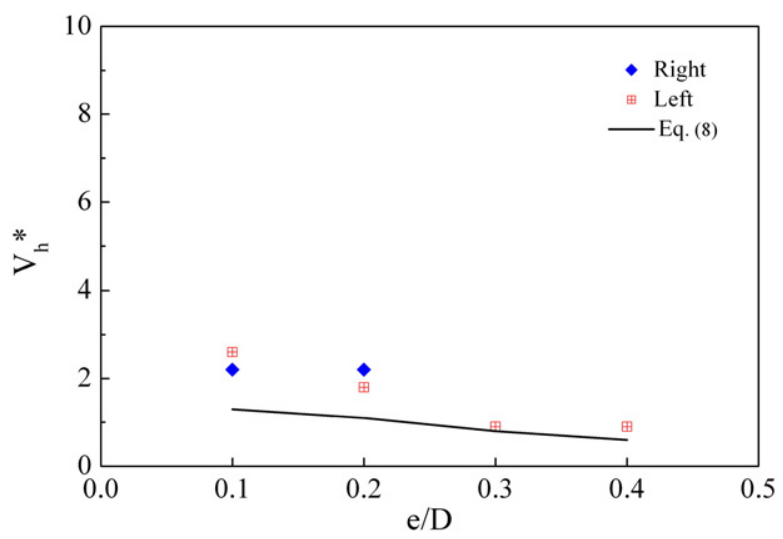

Fig. 16. Comparisons between experimental data and predictions $\left(\alpha=30^{\circ}, \mathrm{KC}=8.7\right)$.

depth below pipelines under combined wave and current conditions reported by Sumer and Fredsøe (2002) (Fig. 2.25, page 51). Such a trend was attributed to a slight displacement of the upstream part of the scour hole in the direction of flow when a current was superimposed on waves so that the flow attack below the pipeline is "weaker" (Sumer and Fredsøe, 2002). It is speculated that the observed trend for scour propagation along the pipeline was due to the same flow/scour mechanism.

Similarly, when the current was superimposed on waves, the resultant orbital velocity was changed. The net orbital velocity in the direction of the waves increased with the passage of wave crests and decreased at wave troughs. This effectively reduced the propagation

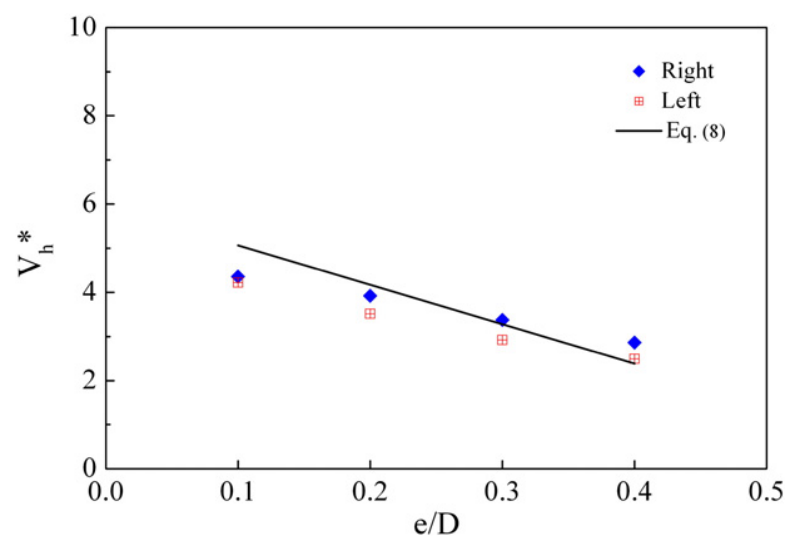

Fig. 17. Comparisons between experimental data and predictions $\left(\alpha=30^{\circ}, \mathrm{KC}=15.8\right)$.

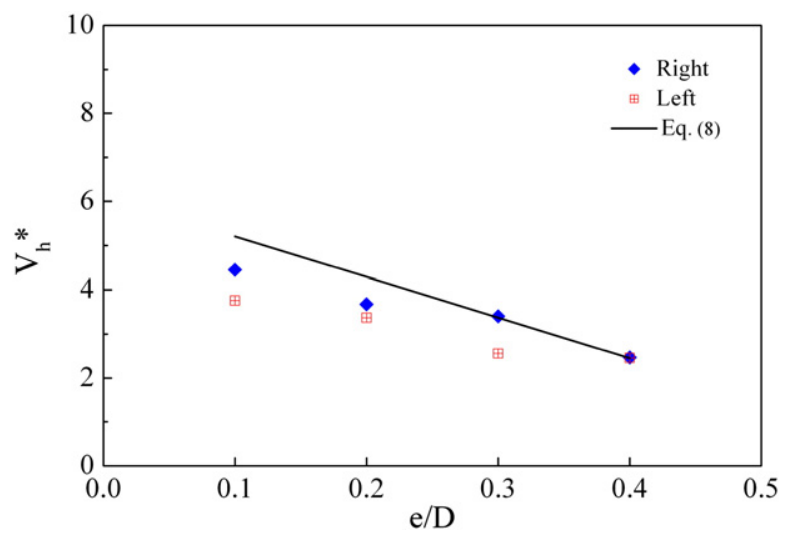

Fig. 18. Comparisons between experimental data and predictions $\left(\alpha=30^{\circ}, \mathrm{KC}=18.0\right.$ ).
Table 5

Test conditions of combined wave and current.

\begin{tabular}{|c|c|c|c|c|c|c|}
\hline Test number & $\mathrm{e} / \mathrm{D}$ & $\frac{\mathrm{U}_{\mathrm{c}}}{\mathrm{m} / \mathrm{s}}$ & $\frac{\mathrm{U}_{\mathrm{w}}}{\mathrm{m} / \mathrm{s}}$ & $\mathrm{m}$ & $\frac{\mathrm{T}}{\mathrm{s}}$ & $\mathrm{KC}$ \\
\hline c4w12t10e1 & 0.1 & 0.29 & 0.12 & 0.71 & 1.0 & 2.3 \\
\hline c4w12t10e2 & 0.2 & 0.29 & 0.12 & 0.71 & 1.0 & 2.3 \\
\hline c4w12t10e3 & 0.3 & 0.29 & 0.12 & 0.71 & 1.0 & 2.3 \\
\hline c4w12t10e4 & 0.4 & 0.29 & 0.12 & 0.71 & 1.0 & 2.3 \\
\hline c4w12t10e5 & 0.5 & 0.29 & 0.12 & 0.71 & 1.0 & 2.3 \\
\hline$c 4 w 15 t 15 e 1$ & 0.1 & 0.29 & 0.18 & 0.62 & 1.5 & 5.3 \\
\hline$c 4 w 15 t 15 e 2$ & 0.2 & 0.29 & 0.18 & 0.62 & 1.5 & 5.3 \\
\hline c4w15t15e3 & 0.3 & 0.29 & 0.18 & 0.62 & 1.5 & 5.3 \\
\hline$c 4 w 15 t 15 e 4$ & 0.4 & 0.29 & 0.18 & 0.62 & 1.5 & 5.3 \\
\hline c4w15t15e5 & 0.5 & 0.29 & 0.18 & 0.62 & 1.5 & 5.3 \\
\hline c4w16t20e1 & 0.1 & 0.29 & 0.34 & 0.46 & 2.0 & 13.6 \\
\hline c4w16t20e2 & 0.2 & 0.29 & 0.34 & 0.46 & 2.0 & 13.6 \\
\hline c4w16t20e3 & 0.3 & 0.29 & 0.34 & 0.46 & 2.0 & 13.6 \\
\hline c4w16t20e4 & 0.4 & 0.29 & 0.34 & 0.46 & 2.0 & 13.6 \\
\hline c4w16t20e5 & 0.5 & 0.29 & 0.34 & 0.46 & 2.0 & 13.6 \\
\hline c5w12t10e1 & 0.1 & 0.42 & 0.11 & 0.79 & 1.0 & 2.2 \\
\hline c5w12t10e2 & 0.2 & 0.42 & 0.11 & 0.79 & 1.0 & 2.2 \\
\hline c5w12t10e3 & 0.3 & 0.42 & 0.11 & 0.79 & 1.0 & 2.2 \\
\hline c5w12t10e4 & 0.4 & 0.42 & 0.11 & 0.79 & 1.0 & 2.2 \\
\hline c5w12t10e5 & 0.5 & 0.42 & 0.11 & 0.79 & 1.0 & 2.2 \\
\hline$c 5 w 15 t 15 e 1$ & 0.1 & 0.42 & 0.24 & 0.63 & 1.5 & 7.3 \\
\hline c5w15t15e2 & 0.2 & 0.42 & 0.24 & 0.63 & 1.5 & 7.3 \\
\hline c5w15t15e3 & 0.3 & 0.42 & 0.24 & 0.63 & 1.5 & 7.3 \\
\hline c5w15te4 & 0.4 & 0.42 & 0.24 & 0.63 & 1.5 & 7.3 \\
\hline c5w15te5 & 0.5 & 0.42 & 0.24 & 0.63 & 1.5 & 7.3 \\
\hline w13t15c70e1 & 0.1 & 0.06 & 0.32 & 0.15 & 2.0 & 12.8 \\
\hline w13t15c70e2 & 0.2 & 0.06 & 0.32 & 0.15 & 2.0 & 12.8 \\
\hline w13t15c70e3 & 0.3 & 0.06 & 0.32 & 0.15 & 2.0 & 12.8 \\
\hline w13t15c70e4 & 0.4 & 0.06 & 0.32 & 0.15 & 2.0 & 12.8 \\
\hline w13t15c70e5 & 0.5 & 0.06 & 0.32 & 0.15 & 2.0 & 12.8 \\
\hline w13t15c180e1 & 0.1 & 0.16 & 0.31 & 0.34 & 1.0 & 6.3 \\
\hline w13t15c180e2 & 0.2 & 0.16 & 0.31 & 0.34 & 1.0 & 6.3 \\
\hline w13t15c180e3 & 0.3 & 0.16 & 0.31 & 0.34 & 1.0 & 6.3 \\
\hline w13t15c180e4 & 0.4 & 0.16 & 0.31 & 0.34 & 1.0 & 6.3 \\
\hline w13t15c180e5 & 0.5 & 0.16 & 0.31 & 0.34 & 1.0 & 6.3 \\
\hline w13t15c370e1 & 0.1 & 0.35 & 0.29 & 0.54 & 1.5 & 8.7 \\
\hline w13t15c370e2 & 0.2 & 0.35 & 0.29 & 0.54 & 1.5 & 8.7 \\
\hline w13t15c370e3 & 0.3 & 0.35 & 0.29 & 0.54 & 1.5 & 8.7 \\
\hline w13t15c370e4 & 0.4 & 0.35 & 0.29 & 0.54 & 1.5 & 8.7 \\
\hline w13t15c370e5 & 0.5 & 0.35 & 0.29 & 0.54 & 1.5 & 8.7 \\
\hline w15t20c90e1 & 0.1 & 0.07 & 0.29 & 0.20 & 2.0 & 11.6 \\
\hline w15t20c90e2 & 0.2 & 0.07 & 0.29 & 0.20 & 2.0 & 11.6 \\
\hline w15t20c90e3 & 0.3 & 0.07 & 0.29 & 0.20 & 2.0 & 11.6 \\
\hline w15t20c90e4 & 0.4 & 0.07 & 0.29 & 0.20 & 2.0 & 11.6 \\
\hline w15t20c90e5 & 0.5 & 0.07 & 0.29 & 0.20 & 2.0 & 11.6 \\
\hline w15t20c230e1 & 0.1 & 0.26 & 0.32 & 0.45 & 1.0 & 6.3 \\
\hline w15t20c230e2 & 0.2 & 0.26 & 0.32 & 0.45 & 1.0 & 6.3 \\
\hline w15t20c230e3 & 0.3 & 0.26 & 0.32 & 0.45 & 1.0 & 6.3 \\
\hline w15t20c230e4 & 0.4 & 0.26 & 0.32 & 0.45 & 1.0 & 6.3 \\
\hline w15t20c230e5 & 0.5 & 0.26 & 0.32 & 0.45 & 1.0 & 6.3 \\
\hline w15t20c450e1 & 0.1 & 0.47 & 0.32 & 0.60 & 2.0 & 12.7 \\
\hline w15t20c450e2 & 0.2 & 0.47 & 0.32 & 0.60 & 2.0 & 12.7 \\
\hline w15t20c450e3 & 0.3 & 0.47 & 0.32 & 0.60 & 2.0 & 12.7 \\
\hline w15t20c450e4 & 0.4 & 0.47 & 0.32 & 0.60 & 2.0 & 12.7 \\
\hline w15t20c450e5 & 0.5 & 0.47 & 0.32 & 0.60 & 2.0 & 12.7 \\
\hline w13t15c450e1 & 0.1 & 0.42 & 0.22 & 0.66 & 2.0 & 8.7 \\
\hline w13t15c450e2 & 0.2 & 0.42 & 0.22 & 0.66 & 1.5 & 6.5 \\
\hline w13t15c450e3 & 0.3 & 0.42 & 0.22 & 0.66 & 1.5 & 6.5 \\
\hline w13t15c450e4 & 0.4 & 0.42 & 0.22 & 0.66 & 1.5 & 6.5 \\
\hline w13t15c450e5 & 0.5 & 0.42 & 0.22 & 0.66 & 1.5 & 6.5 \\
\hline w15t20c300e1 & 0.1 & 0.30 & 0.29 & 0.51 & 2.0 & 11.7 \\
\hline w15t20c300e2 & 0.2 & 0.30 & 0.29 & 0.51 & 2.0 & 11.7 \\
\hline w15t20c300e3 & 0.3 & 0.30 & 0.29 & 0.51 & 2.0 & 11.7 \\
\hline $\mathrm{w} 15 \mathrm{t} 20 \mathrm{c} 300 \mathrm{e} 4$ & 0.4 & 0.30 & 0.29 & 0.51 & 2.0 & 11.7 \\
\hline w15t20c300e5 & 0.5 & 0.30 & 0.29 & 0.51 & 2.0 & 11.7 \\
\hline
\end{tabular}

rate until $U_{c} /\left(U_{c}+U_{w}\right)$ arrived at 0.5 to 0.6 where the propagation rate started to increase thereafter. This is likely that as $U_{c} /\left(U_{c}+U_{w}\right)$ increased over the value of 0.5 , the lee-wake on the upstream side started to disappear and ceased to have influence on the scour process.

The phenomena of onset of scour at multiple locations along the pipeline and the backfill of the initial worm hole deliberately created 
Table 6

Test results under combined wave and current conditions.

\begin{tabular}{|c|c|c|c|c|c|c|c|}
\hline \multirow[t]{2}{*}{ Test number } & \multirow[t]{2}{*}{ KC } & \multirow[t]{2}{*}{$\mathrm{m}$} & \multirow[t]{2}{*}{$\theta \max$} & \multirow{2}{*}{$\frac{\mathrm{V}_{\mathrm{R}}}{\mathrm{mm} / \mathrm{s}}$} & \multirow{2}{*}{$\frac{\mathrm{V}_{\mathrm{L}}}{\mathrm{mm} / \mathrm{s}}$} & \multirow{2}{*}{$\frac{\mathrm{V}_{\mathrm{h}}}{\mathrm{mm} / \mathrm{s}}$} & \multirow{2}{*}{$\frac{\text { Eq. (14) }}{\mathrm{mm} / \mathrm{s}}$} \\
\hline & & & & & & & \\
\hline c4w12t10e1 & 2.3 & 0.71 & 0.11 & \multicolumn{4}{|c|}{ Onset of scour multiple locations } \\
\hline $\mathrm{c} 4 \mathrm{w} 12 \mathrm{t} 10 \mathrm{e} 2$ & 2.3 & 0.71 & 0.11 & 1.01 & $\mathrm{~N} / \mathrm{A}$ & 1.01 & 0.80 \\
\hline c4w12t10e3 & 2.3 & 0.71 & 0.11 & 1.25 & 1.66 & 1.46 & 0.70 \\
\hline c4w12t10e4 & 2.3 & 0.71 & 0.11 & \multicolumn{3}{|c|}{ No scour propagation observed } & 0.60 \\
\hline $\mathrm{c} 4 \mathrm{w} 12 \mathrm{t} 10 \mathrm{e} 5$ & 2.3 & 0.71 & 0.11 & \multicolumn{3}{|c|}{ No scour propagation observed } & 0.50 \\
\hline$c 4 w 15 t 15 e 1$ & 5.3 & 0.62 & 0.15 & \multicolumn{3}{|c|}{ Onset of scour multiple locations } & 0.65 \\
\hline c4w15t15e2 & 5.3 & 0.62 & 0.15 & 1.25 & 0.88 & 1.07 & 0.80 \\
\hline$c 4 w 15 t 15 e 3$ & 5.3 & 0.62 & 0.15 & 1.11 & 0.98 & 1.05 & 0.70 \\
\hline$c 4 w 12 t 15 e 4$ & 5.3 & 0.62 & 0.15 & 0.63 & 0.66 & 0.64 & 0.60 \\
\hline c $4 w 15 t 15 e 5$ & 5.3 & 0.62 & 0.15 & No sco & observed & & 0.50 \\
\hline c4w16t20e1 & 13.6 & 0.46 & 0.27 & Onset & e locations & & 0.75 \\
\hline c4w16t20e2 & 13.6 & 0.46 & 0.27 & 2.17 & 1.40 & 1.79 & 2.09 \\
\hline c4w16t20e3 & 13.6 & 0.46 & 0.27 & 1.37 & 2.21 & 1.79 & 1.83 \\
\hline c4w16t20e4 & 13.6 & 0.46 & 0.27 & 0.93 & 0.64 & 0.79 & 1.57 \\
\hline c4w16t20e5 & 13.6 & 0.46 & 0.27 & No sco & observed & & 1.30 \\
\hline c5w12t10e1 & 2.2 & 0.79 & 0.17 & Onset & e locations & & 3.93 \\
\hline c5w12t10e2 & 2.2 & 0.79 & 0.17 & 3.73 & 2.90 & 3.32 & 2.28 \\
\hline c5w12t10e3 & 2.2 & 0.79 & 0.17 & 3.31 & 2.84 & 3.08 & 2.00 \\
\hline c5w $12 \mathrm{t} 10 \mathrm{e} 4$ & 2.2 & 0.79 & 0.17 & 1.44 & 1.78 & 1.61 & 1.71 \\
\hline c5w12t10es & 2.2 & 0.79 & 0.17 & 1.24 & 0.62 & 0.93 & 1.43 \\
\hline c5w15t15e1 & 7.3 & 0.63 & 0.27 & Onset & e locations & & 2.06 \\
\hline c5w15t15e2 & 7.3 & 0.63 & 0.27 & 2.53 & 3.55 & 3.04 & 2.53 \\
\hline c5w15t15e3 & 7.3 & 0.63 & 0.27 & 6.10 & 3.00 & 4.55 & 2.22 \\
\hline c5w15t15e 4 & 7.3 & 0.63 & 0.27 & 1.02 & 0.84 & 0.93 & 1.90 \\
\hline c5w15t15e 5 & 7.3 & 0.63 & 0.27 & 2.43 & 1.98 & 2.21 & 1.58 \\
\hline w13t15c70e1 & 12.8 & 0.15 & 0.18 & Onset & e locations & & 1.93 \\
\hline w13t15c70e2 & 12.8 & 0.15 & 0.18 & 3.25 & 2.74 & 2.99 & 2.50 \\
\hline w13t15c70e3 & 12.8 & 0.15 & 0.18 & 2.69 & 2.24 & 2.47 & 2.19 \\
\hline w13t15c70e4 & 12.8 & 0.15 & 0.18 & 2.26 & 1.30 & 1.78 & 1.88 \\
\hline w13t15c70e5 & 12.8 & 0.15 & 0.18 & No sco & observed & & 1.56 \\
\hline w13t15c180e1 & 6.3 & 0.34 & 0.28 & Onset & e locations & & 1.86 \\
\hline w13t15c180e2 & 6.3 & 0.34 & 0.28 & 2.17 & 2.16 & 2.17 & 1.99 \\
\hline w13t15c180e3 & 6.3 & 0.34 & 0.28 & 1.03 & 1.02 & 1.02 & 1.74 \\
\hline w13t15c180e4 & 6.3 & 0.34 & 0.28 & 1.31 & 1.06 & 1.18 & 1.49 \\
\hline w13t15c180e5 & 6.3 & 0.34 & 0.28 & No sco & observed & & 1.24 \\
\hline w13t15c370e1 & 8.7 & 0.54 & 0.28 & Onset & e locations & & 3.90 \\
\hline w13t15c370e2 & 8.7 & 0.54 & 0.28 & 1.05 & 0.87 & 0.96 & 2.03 \\
\hline w13t15c370e3 & 8.7 & 0.54 & 0.28 & 0.83 & 0.33 & 0.58 & 1.78 \\
\hline w13t $15 c 370 e 4$ & 8.7 & 0.54 & 0.28 & 0.72 & 0.69 & 0.70 & 1.52 \\
\hline w13t15c370e5 & 8.7 & 0.54 & 0.28 & 0.47 & 0.18 & 0.33 & 1.27 \\
\hline w15t20c90e1 & 11.6 & 0.20 & 0.16 & Onset & e locations & & 1.83 \\
\hline w15t20c90e2 & 11.6 & 0.20 & 0.16 & 3.10 & 2.16 & 2.63 & 1.63 \\
\hline w15t20c90e3 & 11.6 & 0.20 & 0.16 & 2.58 & 2.02 & 2.30 & 1.43 \\
\hline w15t20c90e4 & 11.6 & 0.20 & 0.16 & 2.89 & 2.12 & 2.51 & 1.22 \\
\hline w15t20c90e5 & 11.6 & 0.20 & 0.16 & 1.52 & 1.25 & 1.39 & 1.02 \\
\hline $\mathrm{w} 15 \mathrm{t} 20 \mathrm{c} 230 \mathrm{e} 1$ & 6.3 & 0.45 & 0.32 & Onset & e locations & & 1.46 \\
\hline $\mathrm{w} 15 \mathrm{t} 20 \mathrm{c} 230 \mathrm{e} 2$ & 6.3 & 0.45 & 0.32 & 2.58 & 2.21 & 2.40 & 1.94 \\
\hline $\mathrm{w} 15 \mathrm{t} 20 \mathrm{c} 230 \mathrm{e} 3$ & 6.3 & 0.45 & 0.32 & 2.10 & 1.88 & 1.99 & 1.70 \\
\hline $\mathrm{w} 15 \mathrm{t} 20 \mathrm{c} 230 \mathrm{e} 4$ & 6.3 & 0.45 & 0.32 & 1.49 & 1.06 & 1.27 & 1.46 \\
\hline w15t20c230e5 & 6.3 & 0.45 & 0.32 & 0.84 & 0.69 & 0.76 & 1.21 \\
\hline $\mathrm{w} 15 \mathrm{t} 20 \mathrm{c} 450 \mathrm{e} 1$ & 12.7 & 0.60 & 0.34 & Onset & e locations & & 4.30 \\
\hline w15t20c450e2 & 12.7 & 0.60 & 0.34 & 2.30 & 1.17 & 1.74 & 3.76 \\
\hline w15t20c450e3 & 12.7 & 0.60 & 0.34 & 1.41 & 1.14 & 1.27 & 3.29 \\
\hline w15t20c450e 4 & 12.7 & 0.60 & 0.34 & 1.43 & 0.96 & 1.20 & 2.82 \\
\hline $\mathrm{w} 15 \mathrm{t} 20 \mathrm{c} 450 \mathrm{e} 5$ & 12.7 & 0.60 & 0.34 & No sco & observed & & 2.35 \\
\hline w13t15c450e1 & 8.7 & 0.66 & 0.22 & Onset & e locations & & 4.71 \\
\hline $\mathrm{w} 13 \mathrm{t} 15 \mathrm{c} 450 \mathrm{e} 2$ & 6.5 & 0.66 & 0.24 & 1.85 & 2.20 & 2.03 & 2.20 \\
\hline w13t15c450e3 & 6.5 & 0.66 & 0.24 & 2.35 & 1.58 & 1.96 & 2.09 \\
\hline w13t15c450e4 & 6.5 & 0.66 & 0.24 & No sco & observed & & 1.79 \\
\hline w13t15c450e5 & 6.5 & 0.66 & 0.24 & No sco & observed & & 1.50 \\
\hline w15t20c300e1 & 11.7 & 0.51 & 0.24 & Onset & e locations & & 1.96 \\
\hline $\mathrm{w} 15 \mathrm{t} 20 \mathrm{c} 300 \mathrm{e} 2$ & 11.7 & 0.51 & 0.24 & 1.48 & 1.08 & 1.28 & 1.59 \\
\hline $\mathrm{w} 15 \mathrm{t} 20 \mathrm{c} 300 \mathrm{e} 3$ & 11.7 & 0.51 & 0.24 & 1.40 & 0.96 & 1.18 & 1.39 \\
\hline w15t20c300e 4 & 11.7 & 0.51 & 0.24 & 0.71 & 0.76 & 0.74 & 1.19 \\
\hline w15t20c300e5 & 11.7 & 0.51 & 0.24 & Onset & e locations & & 0.00 \\
\hline
\end{tabular}

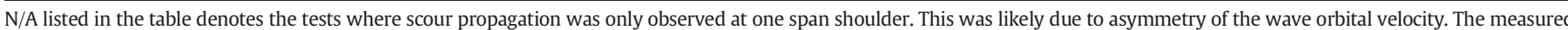
reverse velocity was generally smaller than the forward velocity.

at the centre of the pipeline were also observed in the combined wave and current tests. Similarly, the onset of scour at multiple locations was observed for a few tests all with small initial embedment depths $(<0.2)$ as detailed in Table 7 . The critical velocity for onset of scour under combined waves and currents calculated from the empirical model by Zang et al (2010) were also listed in the last column of Table 7. It can be seen that the measured maximum velocity $U_{c}+U_{m}$ in the tests is larger than the corresponding predicted critical values. 




Fig. 19. Comparisons between experimental data and predictions for combined waves and currents $\left(\mathrm{e} / \mathrm{D}=0.2, \alpha=0^{\circ}, 2.32<\mathrm{KC}<12.36\right)$.

This suggests that the onset of scour at multiple locations was likely due to the piping mechanism discussed in Sumer and Fredsøe (2002).

It was also observed in a number of tests that the initial artificial scour hole in the middle of the pipeline was backfilled soon after the tests started and no scour propagation ever took place. This situation only occurred for the cases with large embedment depths as detailed in Table 8, similar to the observations in wave only tests. Again the limited tests conducted in the present study did not allow quantitative relationships between the critical embedment depth for backfill and flow parameters being established.

3.2.1. Prediction of scour propagation rate under combined wave and current conditions

A predictive model for scour propagation rates under combined wave and current conditions is also proposed here. The derivation of the predictive model followed the same procedure proposed by Cheng et al. (2009) with minor modifications to accommodate for combined wave and current conditions. Similar to the approach for wave only conditions, the two-dimensional equilibrium scour depth under combined wave and current conditions was estimated by the empirical formulae suggested by Sumer and Fredsøe (2002).

$\mathrm{S}_{0}=\mathrm{S}_{\mathrm{cur}} \mathrm{F}$

Where $\mathrm{S}_{\text {cur }}$ is the equilibrium scour depth under steady current only conditions and $\mathrm{F}$ is given by the following empirical equations.

$\mathrm{S}_{0}=\mathrm{S}_{\mathrm{cur}} \mathrm{F}$

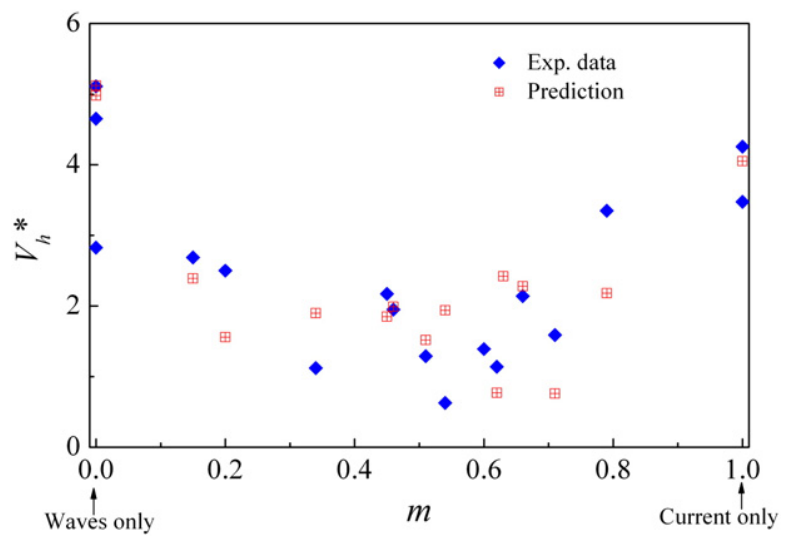

Fig. 20. Comparisons between experimental data and predictions for combined waves and currents $\left(\mathrm{e} / \mathrm{D}=0.3, \alpha=0^{\circ}, 2.32<\mathrm{KC}<12.36\right)$.

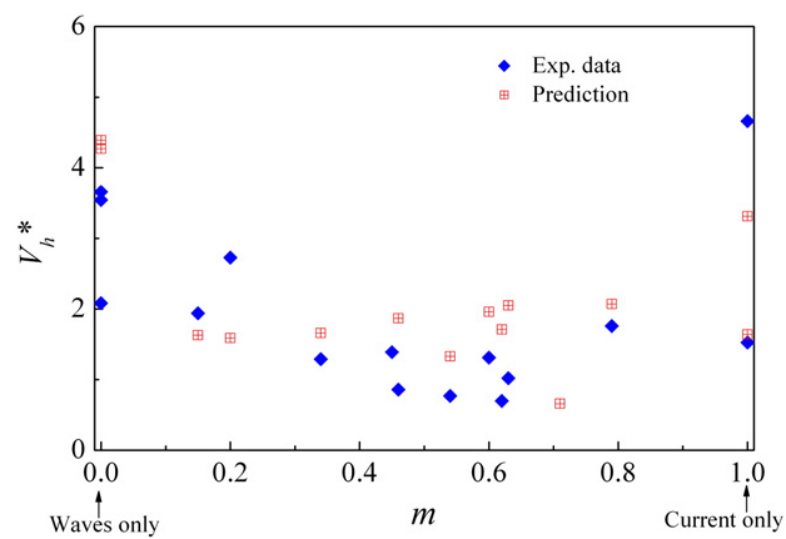

Fig. 21. Comparisons between experimental data and predictions for combined waves and currents $\left(\mathrm{e} / \mathrm{D}=0.4, \alpha=0^{\circ}, 2.32<\mathrm{KC}<12.36\right)$.

$$
\begin{aligned}
& \mathrm{F}=\left\{\begin{array}{cc}
\frac{5}{3}(\mathrm{KC})^{\mathrm{a}} \exp (2.3 b) & 0<\mathrm{m} \leq 0.7 \\
1 & 0.7<\mathrm{m}<1.0
\end{array}\right. \\
& \mathrm{a}=\left\{\begin{array}{cc}
0.557-0.912(\mathrm{~m}-0.25)^{2} & 0 \leq \mathrm{m} \leq 0.4 \\
-2.14 \mathrm{~m}+1.46 & 0.4<\mathrm{m} \leq 0.7
\end{array}\right. \\
& \mathrm{b}=\left\{\begin{array}{cc}
-1.14+2.24(\mathrm{~m}-0.25)^{2} & 0 \leq \mathrm{m} \leq 0.4 \\
3.3 \mathrm{~m}-2.5 & 0.4<\mathrm{m} \leq 0.7
\end{array}\right.
\end{aligned}
$$

Following the same procedure as that proposed by Cheng et al. (2009), the following scour propagation rate along the pipeline was derived:

$\mathrm{V}_{\mathrm{h}}=\mathrm{K}_{\mathrm{WC}}\left(1-\frac{\mathrm{e}}{\mathrm{D}}(1+\sin (\alpha))\right) \frac{\sqrt{\mathrm{g}\left(\rho_{\mathrm{s}} / \rho-1\right) \mathrm{d}_{50}^{3}}}{\mathrm{D} \tan \varphi}\left((1-\mathrm{m}) \theta_{\mathrm{w}}+\mathrm{m} \theta_{\mathrm{c}}\right)^{5 / 3} \mathrm{~F}$,

where $\mathrm{K}_{\mathrm{wc}}$ is a constant, $\phi$ is the angle of repose of the sediment, w is the wave Shields parameter and $\theta_{\mathrm{c}}$ is the Shields parameter due to steady current. Since there was no experimental data available for the time scale $\mathrm{T}^{*}$ under combined wave and current conditions, the following empirical formula was assumed to estimate the time scale $\mathrm{T}^{*}$ used in deriving Eq. (14),

$\mathrm{T}^{*}=\frac{1}{50}\left((1-\mathrm{m}) \theta_{\mathrm{w}}+\mathrm{m} \theta_{\mathrm{c}}\right)^{-5 / 3}$.

The constant $\mathrm{K}_{\mathrm{wc}}$ was obtained by calibrating Eq. (14) against the average scour propagation rate presented in Table 6. It was found that

Table 7

\begin{tabular}{|c|c|c|c|c|c|}
\hline \multirow[t]{2}{*}{ Test number } & \multirow[t]{2}{*}{$\mathrm{m}$} & \multirow[t]{2}{*}{$\mathrm{e} / \mathrm{D}$} & \multirow[t]{2}{*}{$\mathrm{KC}$} & \multirow{2}{*}{$\begin{array}{l}\text { Measured } \\
\left(U_{c}+U_{w}\right) \\
(\mathrm{m} / \mathrm{s})\end{array}$} & \multirow{2}{*}{$\begin{array}{l}\text { Critical } \\
\left(\mathrm{U}_{\mathrm{c}}+\mathrm{U}_{\mathrm{w}}\right) \\
(\mathrm{m} / \mathrm{s})\end{array}$} \\
\hline & & & & & \\
\hline$c 4 w 16 t 20 e 1$ & 0.46 & 0.1 & 13.6 & 0.62 & 0.55 \\
\hline c5w12t10e1 & 0.79 & 0.1 & 2.2 & 0.53 & 0.52 \\
\hline c5w15t15e1 & 0.63 & 0.1 & 7.3 & 0.66 & 0.55 \\
\hline w13t15c370e1 & 0.54 & 0.1 & 8.7 & 0.64 & 0.56 \\
\hline w15t20c230e1 & 0.45 & 0.1 & 6.3 & 0.57 & 0.55 \\
\hline $\mathrm{w} 15 \mathrm{t} 20 \mathrm{c} 450 \mathrm{e} 1$ & 0.60 & 0.1 & 12.7 & 0.79 & 0.55 \\
\hline $\mathrm{w} 13 \mathrm{t} 15 \mathrm{c} 450 \mathrm{e} 1$ & 0.66 & 0.1 & 8.7 & 0.63 & 0.55 \\
\hline w15t20c300e1 & 0.51 & 0.1 & 11.7 & 0.60 & 0.56 \\
\hline
\end{tabular}

Test cases with onset of scour at multiple locations along the pipeline by combined waves and currents. 
Table 8

Test cases with no scour propagation due to the initial worm hole backfill by combined waves and currents.

\begin{tabular}{llllr}
\hline Test Number & $\mathrm{m}$ & $\mathrm{e} / \mathrm{D}$ & $\mathrm{U}_{\mathrm{c}}+\mathrm{U}_{\mathrm{w}}(\mathrm{m} / \mathrm{s})$ & $\mathrm{KC}$ \\
\hline c4w12t10e4 & 0.71 & 0.4 & 0.11 & 2.3 \\
c4w12t10e5 & 0.71 & 0.5 & 0.11 & 2.3 \\
c4w15t15e5 & 0.62 & 0.5 & 0.15 & 5.3 \\
c4w16t20e5 & 0.46 & 0.5 & 0.27 & 13.6 \\
w13t15c70e5 & 0.15 & 0.5 & 0.18 & 12.8 \\
w13t15c180e5 & 0.34 & 0.5 & 0.28 & 6.3 \\
w15t20c450e5 & 0.60 & 0.5 & 0.34 & 12.7 \\
w13t15c450e4 & 0.66 & 0.4 & 0.24 & 6.5 \\
w13t15c450e5 & 0.66 & 0.5 & 0.24 & 6.5 \\
\hline
\end{tabular}

Eq. (14) showed reasonable correlations with the experimental results with $\mathrm{K}_{\mathrm{wc}}=148.0$. The predictions of scour propagation rate using Eq. (14) are compared with experimental data in Figs. 19, 20 and 21 for e/D $=0.2,0.3$ and 0.4 correspondingly. It is seen from Figs. 19 to 21 that the empirical Eqs. (14) predicted the trend of variations of scour propagation rate with velocity ratio quite well. The scatter of the experimental data shown in Figs. 19 to 21 was due to the differences in the KC number and Shields parameter of the test data.

\section{Conclusions}

1. The scour hole was found to propagate at a constant velocity along a rigid pipeline under wave only conditions.

2. The scour propagation rate along the pipeline under wave only conditions increases with KC number and Shields parameter, and decreases with embedment depth.

3. The rates of scour propagation towards both directions along the pipeline are almost identical, regardless of the wave incident angles. The experimental results also suggest that the scour propagation rate decreases with the increase of wave incident angle.

4. The predictive model developed by Cheng et al. (2009) was modified to accommodate wave only and combined wave and current conditions. The predictions using modified models showed good agreement with the experimental results.

5. The effects of superimposing waves onto current under combined wave and current conditions suggest a general trend that the scour propagation rate first decreases as the current velocity increases until $\mathrm{m}=\mathrm{U}_{\mathrm{c}} /\left(\mathrm{U}_{\mathrm{c}}+\mathrm{U}_{\mathrm{w}}\right) \approx 0.6$, then it starts to increase thereafter.

6. The onset of scour at multiple locations along the pipeline occurred simultaneously in a number of tests under wave only and combined wave and current conditions at small embedment depths (typically $\mathrm{e} / \mathrm{D}=0.1$ ). It is believed that the onset of scour was induced by the piping mechanism that was observed previously in two dimensional scour tests.

7. Sediment backfill of the initial worm hole occurred in a number of tests under both wave only and combined wave and current conditions with large embedment depths (typically e/D $=0.5$ ), resulting in no scour propagation along the pipeline. It is believed that the critical embedment depth at which backfill of sediments takes place is dependent on KC number, velocity ratio and flow/ wave incident angles.

8. It should be noted that all the tests conducted under combined wave and current conditions in the present study were carried out with co-linear waves and currents. Cautions should be exercised when the results are applied to conditions outside of the limit of test conditions.

\section{Acknowledgements}

The authors would like to acknowledge the support from the Australian Research Council for their support through a Discovery
Project (LP0989936), National Natural Science Foundation of China (Grant No. 51109202) and Dalian University of Technology (DUT).

\section{References}

Bernetti, R., Bruschi, R., Valentini, V., Venturi, M., 1990. Pipelines placed on erodible seabeds. Proc. 9th International Conference on Offshore Mechanics and Artic Engineering, vol. V. ASME, Houston, TX, pp. 155-164.

Brørs, B., 1999. Numerical modelling of flow and scour at pipelines. J. Hydraul. Eng. ASCE 125 (5), 511-523.

Cevik, E., Yuksel, Y., 1999. Scour under submarine pipelines in waves in shoaling conditions. J. Hydraul. Eng. ASCE 125 (1), 1-11.

Cheng, L., Yeow, K., Zang, Z., Teng, B., 2009. Three-dimensional scour below pipelines in steady currents. Coast. Eng. 56 (5-6), 577-590.

Chiew, Y.-M., 1990. Mechanics of local around submarine pipeline. J. Hydraul. Eng. ASCE 116 (4), 515-529.

Fredsøe, J., Hansen, E.A., Mao, Ye, Sumer, B.M., 1988. Three-dimensional scour below pipelines. Trans. ASME J. Offshore Mech. Arct. Eng. 110, 373-379.

Fredsøe, J., Sumer, B.M., Arnskov, M., 1992. Time scale for wave/current scour below pipelines. Int. J. Offshore Polar Eng. 2 (2), 13-17.

Gokce, T., Gunbak, A.R., 1991. Time scale for wave/current scour below pipelines. Int J. Offshore Polar Eng. 2 (2), 13-17.

Hansen, E.A., 1992. Scour below pipelines and cables. A Simple Model. 11th Offshore Mechanics and Artic Engineering Conference. Pipeline Technol., vol. V-A. ASME, Calgary, Canada, pp. 133-138.

Hansen, E.A., Staub, C., Fredsøe, J., Sumer, B.M., 1991. Timedevelopment of scour induced free spans of pipelines. Proc., 10th Conf. on Offshore Mechanics and Arctic Engineering, Pipeline Technology, Vol. V, ASME, New York, pp. 25-31.

Jas, E., O'Brien, D., Fricke, R., Gillen, A., Cheng, L., White, D., Palmer, A., 2012. Pipeline stability revisited. J. Pipeline Eng. 12 (No. 4), 259-268.

Jensen, B.L., Sumer, B.M., Fredsøe, J., 1989. Turbulent oscillatory boundary layers at high Reynolds numbers. J. Fluid Mech. 206, 265-297.

Li, F., Cheng, L., 1999. A numerical model for local scour under offshore pipelines. J. Hydrol. Eng. 125 (4), 400-406.

Li, F., Cheng, L., 2002. Mathematical modelling of time-dependent scour below offshore pipelines. Personal Communication.

Liang, D., Cheng, L., 2005a. A numerical model for wave-induced scour below a submarine pipeline. J. Waterw. Port Coast. Ocean Eng. ASCE 13 (5).

Liang, D.F., Cheng, L., 2005b. Numerical modelling of scour below a pipeline in currents. Part I: flow simulation. Coast. Eng. 52 (1), 25-42.

Liang, D.F., Cheng, L., Li, F., 2005. Numerical modelling of scour below a pipeline in currents. Part II: scour simulation. Coast. Eng. 52 (1), 43-62.

Lucassen, R.J., 1984. Scour underneath submarine pipelines. Report No. PL-4 2A. Neth. Mar. Tech. Res. Netherlands Industrial Council for Oceanology, Delf University of Technology, Delf, the Netherlands (Sep. 1984. Student Thesis supervised by E.W. Bijker and W. Leeuwenstein).

Palmer, A.C., 1996. A flaw in the conventional approach to stability design of pipelines. Proc. Offshore Pipeline Technology Conf., Amsterdam, the Netherlands.

Soulsby, R., 1997. Dynamics of marine sands: a manual for practical applications. Thomas Telford.

Sumer, B.M., Fredsøe, J., 1990. Scour below pipelines in waves. J. Waterw. Port Coast. Ocean Eng. ASCE 116 (3), 307-323.

Sumer, B.M., Fredsøe, J., 1991. Onset of scour below a pipeline exposed to waves. Int J. Offshore Polar Eng. 1 (3), 189-194.

Sumer, B.M., Fredsøe, J., 1996. Scour around pipelines in combined waves and current Proc. 7th International Conference on Offshore Mechanics and Arctic Engineering Conference. Pipeline Technol., vol. V. ASME, Florence, Italy, pp. 595-602.

Sumer, B.M., Fredsøe, J., 1997. Hydrodynamics around cylindrical structures. World Scientific. (xviii +530 pp.).

Sumer, B.M., Fredsøe, J., 2002. The Mechanics of Scour in the Marine Environment. World Scientific, Singapore.

Sumer, B.M., Truelsen, C., Sichmann, T., Fredsøe, J., 2001. Onset of scour below pipelines and self-burial. Coast. Eng. 42 (4), 213-235.

Wu, Y., Chiew, Y.M., 2012. Three-dimensional scour at submarine pipelines. J. Hydraul. Eng. 138 (9), 788-795

Wu, Y., Chiew, Y.M., 2013. Mechanics of three-dimensional pipeline scour in unidirectional current. J. Pipeline Syst. Eng. Pract. 4, No. 1.

Zang, Z., Cheng, L., Zhao, M., Liang, D., Teng, B., 2009. A numerical model for onset of scour below offshore pipelines. Coast. Eng. 56 (4), 458-466.

Zang, Z., Cheng, L., Zhao, M., 2010. Onset of scour below pipeline under combined waves and current. Proc. 29th International Conference on Offshore Mechanics and Artic Engineering Conference, 1. ASME, Shanghai, China, pp. 483-488.

\section{Notation}

$a, b, F$ : coefficients in prediction of scour propagation velocity under combined wave and current

$A D V$ : acoustic Doppler velocimeter

COP: critical onset parameter

$d_{50}$ : grain median size

$D$ : diameter of pipeline

e: embedment depth

$f_{w}$ : wave friction factor 
g: acceleration due to gravity

$H$ : wave height

$k_{s}$ : Nikuradse equivalent sand grain roughness

$K$ : constant calibration parameter for scour propagation rate for waves

$K_{w c}$ : constant calibration parameter for scour propagation rate for combined wave and current

KC: KC number

$m$ : ratio of velocity induced by current component to the total velocity, $=\mathrm{U}_{\mathrm{c}} /\left(\mathrm{U}_{\mathrm{c}}+\mathrm{U}_{\mathrm{w}}\right)$

$n$ : porosity of the sediment

OP: onset parameter

$s$ : specific gravity of sediment grains

$S$ : scour depth below pipeline

$S_{R}$ : propagation distance of scour hole to right of pipeline

$S_{L}$ : propagation distance of scour hole to left of pipeline

$S_{0}$ : two-dimensional scour depth
$S_{\text {cur: }}$ : equilibrium scour depth under steady current only conditions

$t$ : time

T: wave period

$U_{c}$ : velocity induced by current component

$U_{w}$ : wave orbital velocity at $25 \mathrm{~mm}$ above seabed

$V_{h}, V_{L}, V_{R}$ : scour propagation velocity along the pipeline; subscript $\mathrm{h}, \mathrm{R}, \mathrm{L}$ denotes that for

the averaged value, right side of pipeline and left pipeline, respectively.

$V_{h}{ }^{*}, V_{L}{ }^{*}, V_{R}{ }^{*}$ : normalized scour propagation velocity along the pipeline

$\alpha$ : angle of attack

$\phi:$ angle of repose

$\theta_{w}:$ Shields parameter under waves

$\tau_{w}$ : wave-induced shear stress

$\rho$ : water density

$\rho_{s}$ : density of sediment grains 